\title{
Organic and Inorganic Fouling in Heat Exchangers - Industrial Case Study: Analysis of Fouling Rate
}

Emilio Diaz-Bejarano ${ }^{1,2}$, Elaheh Behranvand ${ }^{3}$, Francesco Coletti ${ }^{2,4}$, Mohammad Reza Mozdianfard $^{3}$, and Sandro Macchietto ${ }^{1,2 *}$

${ }^{1}$ Department of Chemical Engineering, Imperial College London, London SW7 2AZ, UK

${ }^{2}$ Hexxcell Ltd., Innovation Hub, Imperial College - White City Campus, 80 Wood Lane, London W12 OBZ, UK.

${ }^{3}$ Chemical Engineering Dep., University of Kashan, Kashan, 87317-53153, Iran.

${ }^{4}$ College of Engineering, Design and Physical Sciences, Brunel University London, Uxbridge, UB8 3PH, UK

*s.macchietto@imperial.ac.uk

KEYWORDS: energy recovery, crude oil, fouling, inorganics, heat exchanger, monitoring, diagnosis.

\section{ABSTRACT}

Fouling rates in refinery heat exchangers with mixed organic/inorganic deposits (frequent in practice) are estimated using a comprehensive model-based thermo-hydraulic methodology combining data-driven measurements analysis with advanced models. An industrial case study for a heat exchanger over 4-years demonstrates the method. Following an analysis of the fouling state, the dynamic analysis here estimates organic and inorganic fouling rates using constant or time-varying proportionality ratios. Base-line organics deposition rate is described by a typical correlation, inorganics deposition as a perturbation with constant or time-varying proportionality ratios. Deposition rate parameters are estimated from measured pressure drops and validated against temperatures. Results show that: the deposition rate ratio varied substantially over time, revealing acute inorganic deposition periods; accounting for inorganics explains well both thermal and 
hydraulic performances; the time-varying ratio provided a good fit of the data; this is a highly promising new method for predictive monitoring, detection and diagnosis of fouling.

\section{INTRODUCTION}

The efficient use of energy remains a key issue in all chemical industries. Energy integration and recovery by means of extensive heat exchanger networks are effective ways to maximize the use of energy available within process streams and reduce operating costs. However, unwanted deposition of material on heat transfer surfaces (fouling) dramatically reduces heat exchangers efficiency leading not only to greater external utilities consumption, but also to operational problems, reduced throughput, and periodic shutdown of individual or entire units for cleaning. This is particularly important in the crude distillation unit of refineries, where extra fuel consumption, reduced production and $\mathrm{CO}_{2}$ emissions translate in losses in the order of millions of dollars per annum ${ }^{1,2}$.

To minimize fouling and increase energy efficiency, it is necessary to rapidly monitor its occurrence, diagnose the underlying causes leading to deposition, link them to measurable operating conditions, reliably predict the future performance of heat exchangers as fouling builds up and ultimately, inform suitable strategies for manipulating controllable operating variables so as to mitigate its formation or effects. The analysis of fouling should ideally use primary measurements and/or derived, reliable fouling indicators to reveal variations and characteristics of fouling over time, its dependence on process variables, and effects on performance. For industrial applications, the aim is to develop predictive models capable of anticipating future performance, thereby enabling the optimisation of cleaning schedules and other mitigation remedies ${ }^{1,3-6}$. The first step in any such scheme is to establish with confidence the current fouling conditions of an exchanger from the analysis of available data.

The analyses of fouling state and fouling rate in crude oil preheat trains are usually performed by means of the thermal fouling resistance $\left(R_{f}\right)$, calculated the from temperature and flowrate measurements, and the rate of change in fouling resistance $\left(d R_{f} / d t\right)$, respectively. With respect to the fouling state, $R_{f}$ has the disadvantage of not providing independent information about the deposit thickness, composition, and history ${ }^{7}$, as well as other disadvantages pointed out by several authors ${ }^{8-}$ 
${ }^{10}$. With respect to the fouling rate, most past works focused on development and fitting of semiempirical models for chemical reaction fouling that relate $d R_{f} / d t$ to process conditions (e.g. ${ }^{6,9,11-16}$ ). Extensive reviews on the subject can be found in the literature ${ }^{10,17-19}$. This mechanism, traditionally considered to be dominant in crude oil fouling, assumes the build-up of organic deposits over long periods of time (months, years). The thermal conductivity of such deposit has therefore been assumed to be within the range recommended for organic hydrocarbon deposits (e.g. ${ }^{20,21}$ ), based on which, in a few modelling studies investigating the hydraulic impact of crude oil fouling (e.g. ${ }^{14,22,23}$ ), the $R_{f}$ was used to estimate the deposit thickness and its impact on the pressure drop. As discussed later in this section, ref. ${ }^{24}$ highlighted how this approach may be not just inaccurate in predicting both fouling state and pressure drops, but also misleading (see also discussions in refs. ${ }^{24-26}$ ).

A more comprehensive method for fouling analysis based on plant data was presented by DiazBejarano et al. ${ }^{26}$ which includes two main stages: i) analysis of fouling state; ii) analysis of fouling rate. The analysis is based on applying advanced deterministic models of shell-and-tube heat exchangers undergoing fouling in combination with thermo-hydraulic measurements. The application presented is to crude oil refining, however the method is generally applicable to fouling in heat exchangers. Diaz-Bejarano et al. ${ }^{7}$ presented an application of stage i), analysis of fouling state, to a comprehensive industrial case study involving a pre-flash, post-desalter (PDPF) heat exchanger, over a four year period, showing that extent, characteristics and transformations of fouling deposit over time could be well characterised. The combined use of temperature, flowrate and tube-side pressure drop measurements, together with the advanced modelling framework, allowed obtaining the time variation of the apparent deposit thickness and conductivity, shown in Figure 1 (the apparent terminology is used to indicate quantities which lump into a single number, the overall average of a spatially distributed, heterogeneous deposit). For the case considered, this analysis led to two key conclusions. First, the time-profile of the estimated deposit thickness indicated an overall falling shape in the deposit growth, but with several acute deposition periods detected. Second, it revealed that the apparent deposit thermal-conductivity varied over time, indicating a non-homogeneous deposit in nature. These two aspects convey considerable additional useful information compared to those derived from traditional fouling resistance-based analyses (see reviews in refs. ${ }^{24,26,27}$ ) which 
cannot cope with changes in foulant composition and reliably differentiate between periods of different fouling propensity.

In ref. ${ }^{7}$, the deposit was modelled as a binary mixture of low-conductivity organic and highconductivity inorganic materials. The deposition of layers with distinct inorganic-organic proportions in different periods was identified as the underlying cause of the time-variation in apparent conductivity. Inorganic materials, often present in crude oil fouling deposits ${ }^{9,28-34}$, are characterized by higher conductivity $(1-5 \mathrm{~W} / \mathrm{mK})$ than organic matter $(0.15-0.25 \mathrm{~W} / \mathrm{mK}$ and up to $1 \mathrm{~W} / \mathrm{mK}$ if aged), based on literature values ${ }^{3,35-37}$. Using the multi-component deposit model by Diaz-Bejarano et al. ${ }^{27}$, a radial conductivity profile of the deposit was reconstructed, which was translated in turn into a radial concentration profile using suitable thermal-conductivity mixing models. Figure 2(a), obtained with two thermal-conductivity mixing models (EMT and CC), showed that the deposit is not uniform but grows in layers of different compositions. Similar to growth rings in a tree, the deposit layers thus reflect the operation and deposition history. Layers with greater concentration of inorganics were shown to form simultaneously as the acute fouling episodes previously detected. Newer layers contained gradually less inorganics, creating a heat transfer limiting effect at the top of the layer, leading to a decreasing trend in the apparent thermal-conductivity (Figure 1). Results of this datadriven analysis were well supported by experimental characterization of the deposits collected when the exchanger was opened after four years of operation. In particular, the concentration profiles obtained from the local conductivity profile with the EMT and CC thermal-conductivity mixing models, shown in Figure 2(a), provided surprisingly good agreement with the experimental analysis of the radial concentration distribution of inorganic and organic matter through the deposit. The average inorganic content estimated with the EMT and CC models was $49.5 \mathrm{wt} \%$ and $52_{\mathrm{wt}} \%$, respectively, while the chemical characterization of the deposits collected during the shutdown of the double-shell exchanger at the end of that same period revealed an average inorganic content between $55-61.7 \mathrm{wt} \%$.

Increased conductivity of crude oil fouling deposits with high inorganic content and formation of complex layering structures following "abnormal" deposition events were anticipated by DiazBejarano et al. ${ }^{24}$ in a simulation paper. There, it was highlighted that ignoring the presence of inorganic foulants when assessing/predicting the thermo-hydraulic performance of heat exchangers 
may lead to significant deviations of model responses from the actual fouling behaviour and to the poor/wrong detection of abnormal fouling events. The path towards the development of new modelbased monitoring systems was outlined, whereby a) predictive fouling rate models would provide the expected fouling behaviour and exchanger performance under normal situations and b) a comparison of such predicted baseline with actual thermo-hydraulic measurements could then help detect abnormal situations. A useful visualization of all these effects and interactions was achieved using the TH- $\lambda$ plot ${ }^{38,39}$.

This paper presents an industrial application of the second stage of the methodology suggested previously ${ }^{26}$, in particular the analysis of fouling rate, in the same PDPF heat exchanger studied by Diaz-Bejarano et al. ${ }^{7}$. Such analysis aims at characterising the deposition rates and is performed in two sequential steps ${ }^{26}$ :

\section{- Step ii-1. selection of deposition rate model}

- Step ii-2. estimation and testing of fouling parameters in the deposition rate models from available plant measurements.

(Previous analysis steps presented in ${ }^{7}$, included: i-1. system definition; i-2. data filtering and error analysis; and i-3. dynamic analysis of fouling state).

The aim here is to demonstrate via a demanding industrial case study, the ability to identify mechanistic deposition models that simultaneously capture the observed gradual decay in both thermal and hydraulic performance.

One of the main challenges addressed in this work is the description of deposition rates for mixed organic-inorganic species from crude oil. Although some progress in understanding deposition in such conditions has been achieved in recent years ${ }^{34,40,41}$, modelling of the kinetics for inorganics deposition is almost unexplored. Furthermore, detailed description of deposition of multiple fouling species, following multiple mechanisms, would require a detailed compositional characterization of the oil. Unfortunately, this information is often unavailable in industrial plants (or only available in details insufficient to establish a relationship with confidence; or inaccessible due to confidentiality reasons).

In the absence of reliable mechanistic deposition models for inorganics in crude oil, a pragmatic approach proposed previously ${ }^{24}$ is followed here. This involves using a typical crude oil fouling 
correlation to describe the deposition rate of the organic foulant (as function of operating conditions) and an inorganic-to-organic deposition rate proportionality ratio (either fixed or time-varying) to calculate the deposition rate of the inorganic species.

This paper is organized as follows. In Section Modelling Framework, the general modelling framework used is briefly introduced to the reader. Section Deposition rate model for mixed inorganic-organic deposition describes a deposition rate model for mixed organic-inorganic deposition, with several alternatives, whereby the inorganic deposition rate is viewed as a disturbance with respect to a baseline provided by a reference deposition rate. Section Case Study: Thermohydraulic Analysis of Fouling Rate presents the results of the industrial case study. First, the results from the analysis of the fouling state (mentioned above) are used to obtain the apparent fouling rate and the inorganic-to-organic proportionality ratio. Step ii-1. selection of deposition rate model discusses how this enables to elucidate the likely succession of events, possible deposition mechanisms and how these relate to the deposition models proposed. In Step ii-2. estimation and testing of fouling parameters, the deposition model, with its various alternatives, is fitted to plant data, for the industrial case study. The results are compared with the measured data, followed by a discussion of the potential of the method for monitoring organic and inorganic fouling and some concluding notes.

\section{MODELLING FRAMEWORK}

The modelling framework used includes i) the dynamic, distributed heat exchanger model by Coletti and Macchietto ${ }^{42}$ - implemented in Hexxcell Studio ${ }^{\text {TM }} 43$; ii) the multi-component deposit formulation by Diaz-Bejarano et al. ${ }^{27}$ and iii) several deposit thermal-conductivity mixing models, introduced in ref. ${ }^{7}$. The main equations in the heat exchanger and deposit models (refs. ${ }^{7,27,42,44-46}$ ) are summarized in Table 1. While in ref. ${ }^{7}$ the deposit characteristics were extracted from plant data, here the models are solved using a "prediction" solution type ${ }^{26}$ from which:

a) the amount and composition of the material building up on top of the old layer is given by a deposition model (which determines the deposit thickness and boundary condition in the mass balance equations in Table 1); 
b) the results from a) determine the evolution over time of the deposits characteristics, i.e. layer thickness and local thermal-conductivity;

c) the exchanger thermo-hydraulic performance (heat duty and tube-side pressure drop) is calculated over time, determined by the characteristics of the deposit and the operating conditions of the inlet streams.

The deposit is represented as a continuum composed of differential sublayers in the radial direction. Each differential element is characterized by the concentration of various fouling species, which determines the physical properties of that deposit zone (e.g. the local thermal-conductivity). This approach assumes that the elements composing the deposit microstructure (e.g. particles, pores, etc.) are of much smaller size than the deposit itself. Furthermore, for a given axial location in a tube, deposition rate and deposit are assumed to be axisymmetric, i.e. symmetric in the angular direction. These assumptions reasonably agree with the experimental results presented in ref. ${ }^{7}$, where slices of intact deposit were analysed with Scanning Electron Microscopy equipped with Energy-Dispersive Xray spectroscopy at several angular locations. Apart from fouling composition, the deposition rate is also a function of operating conditions and is calculated locally in the axial direction, i.e. the variation in deposit thickness differs along the tubes and for each pass in the heat exchanger.

Based on ref. ${ }^{7}$, the deposit is modelled as a mixture of two pseudo-components: a lowconductivity organic $\left(\lambda_{\text {org }}=0.2 \mathrm{~W} / \mathrm{mK}\right)$ and a high-conductivity inorganic material $\left(\lambda_{\text {inorg }}=4 \mathrm{~W} / \mathrm{mK}\right)$. The organic phase includes the overall contribution of organic carbonaceous deposits, including small quantities of free oil that could be trapped in the pores of the deposit structure. The inorganic phase includes the overall contribution of all inorganic species. The local conductivity $\left(\lambda_{l}\left(z, \tilde{r}_{l}\right)\right)$ is then calculated as function of the local proportion of the organic and inorganic fouling phases at each point in the deposit $\left(x_{l, i}\left(z, \tilde{r}_{l}\right)\right)$ using the two thermal-conductivity mixing models that provided better results in ref.': the Effective Media Theory (EMT) and the Co-continuous model (CC) ${ }^{47}$ (see equations in Table 1). 


\section{DEPOSITION RATE MODEL FOR MIXED INORGANIC- ORGANIC DEPOSITION}

The proportionality approach to model the mixed inorganic and organic deposition ${ }^{24}$ is extended to allow simulating distinct relationships between the deposition rates of the two pseudo-components.

First, the total net deposition rate $\left(n_{f}[=] \mathrm{kg} \mathrm{m}^{-2} \mathrm{~s}^{-1}\right)$, at an axial location $z$ of tube-pass $n$, is defined as:

$$
n_{f, n}(z)=n_{f, \text { inorg,n }}(z)+n_{f, \operatorname{org}, n}(z)
$$

where $n_{f, \text { inorg }}$ and $n_{f, \text { org }}$ are the deposition rates of the inorganic and organic components, respectively. The deposition of inorganics is modelled assuming a proportionality of an inorganic pseudocomponent (representing the overall contribution of all inorganic species) with respect to the organic deposition:

$$
n_{f, \text { inorg }, n}(z)=p_{\text {inorg }} n_{f, \text { org }, n}(z) \rho_{\text {inorg }} / \rho_{\text {org }}
$$

where $\rho$ is the density of the corresponding pseudo-component and $p_{\text {inorg }}$ is the proportionality ratio. The proportionality ratio, $p_{\text {inorg }}$, thus describes the inorganic deposition rate as a "relative" rate with respect to the organic deposition rate. Such approach is often used in modelling, for example, in Arrhenius-type rate models ${ }^{48}$. In principle, the proportionality ratio is not constant, nor known $a$ priori.

In ${ }^{24}$, a constant proportionality ratio was imposed a-priori, with values chosen parametrically in order to simulate a number of scenarios of interest. Here, the approach adopted is to obtain this ratio from measured plant data. The local composition at each deposit depth is a consequence of the relative deposition rate of inorganics and organics at the time when that deposit is settled. Consequently, an inorganic-to-organic deposition rate proportionality ratio can be calculated directly from the concentration profile in Figure 2(a). The deposition rate ratio for the inorganic portion, $p_{\text {inorg }}$, at each point in the deposit radial profile, representing the overall contribution to the volume-based deposition rate of the inorganic species, is:

$$
p_{\text {inorg }}=\frac{n_{f, \text { inorg }} / \rho_{i}}{n_{\text {org }} / \rho_{\text {org }}}=\frac{x_{l, \text { inorg }}}{x_{l, \text { org }}}
$$


Finally, a typical crude oil fouling correlation is used as a baseline for the fouling dynamics. In particular, the functional form of the threshold model by Panchal et al. ${ }^{12}$ is adopted for the baseline or reference deposition rate, $n_{\text {ref }}$, as:

$$
n_{r e f, n}(z)=\alpha^{\prime} R e_{n}(z)^{-0.66} \operatorname{Pr}_{n}(z)^{-0.33} \exp \left(\frac{-E_{f}}{R_{g} T_{f i l m, n}(z)}\right)-\gamma^{\prime} \tau_{w, n}(z)
$$

where $R e$ is the Reynolds number, $P r$ the Prandtl number, $T_{\text {film }}$ the film temperature, $\tau_{w}$ the wall shear stress (at surface of the deposit), $z$ the axial coordinate, $n$ the pass number, and $\alpha^{\prime}, E_{f}, \gamma^{\prime}$ are three adjustable parameters. This correlation is widely accepted in describing chemical reaction fouling in oil systems where such fouling mechanism is typically assumed for organic deposition. It is worth noting that this was originally derived based on some assumptions about the likely rate-limiting steps in a reaction/transport mechanism, so its interpretation as a deposition "rate" rather than as a thermal resistance is appropriate. Acknowledging other possible scenarios, in the simplest case we have $n_{f, \text { org }}(z)=n_{\text {ref,n }}(z)$, i.e. the organics deposition rate is given by the reference baseline, the approach adopted in ref. ${ }^{24}$, but other situations are possible. Three alternative relative deposition models are considered here and tested in the case study:

\section{1) Uniform mixture approximation:}

A uniform binary organic-inorganic mixture is assumed to represent the deposit average properties. This may be interpreted as assuming a single, combined fouling mechanism for both the organic and inorganic portions, i.e. a deposit with uniform composition (e.g. as in ${ }^{34}$ ). Assuming further that the combined mechanism deposition rate depends on operating conditions according to Eq. (4) and that the inorganic-organic proportionality ratio is constant, we have:

$$
n_{f, \text { org }}=n_{\text {ref }} \quad ; \quad p_{\text {inorg }}=\text { constant }
$$

\section{2) Time-varying inorganic-to-organic deposition ratio with independent mechanisms:}

This system is modelled as a binary organic-inorganic mixture with time-varying, rather than constant, deposition proportionality ratio. The organic deposition rate is assumed to be well described by the Ebert-Panchal correlation and to mainly depend upon temperature and shear rate (in other words, it follows a chemical reaction mechanism). The inorganic pseudo-component is assumed to 
deposit according to Eq. 2, with the $p_{\text {inorg }}$ time profile being obtained from the dynamic fouling analysis of plant data (Figure 2a, Eq. 3). This implies that inorganics deposition not only follows a similar dependence on temperature and shear as the organics, but also depends on other unknown factors that are responsible for deviations from the main trend (e.g. acute deposition periods). Moreover, it implies that the organic deposition is independent of the inorganics concentration. Consequently:

$$
n_{f, \text { org }}=n_{\text {ref }} \quad ; \quad p_{\text {inorg }}=p_{\text {inorg }}(t)
$$

\section{3) Time-varying inorganic-to-organic deposition ratio with reinforcing interaction:}

Here, as in the deposition model 2) above, a binary organic-inorganic mixture with time-varying deposition proportionality ratio is assumed, with the inorganic pseudo-component depositing according to the same $p_{\text {inorg }}$ time profile. The organic deposition rate is assumed to be well described by the Ebert-Panchal correlation, as before, although reinforced by the presence of inorganics. This means that the overall deposition rate of organics increases in the presence of inorganics, either because the inorganic species directly promote chemical reaction, as reported for iron species in ${ }^{49,50}$, or because organic deposition follows several routes (e.g. chemical reaction and the combined inorganic-organic deposition mechanism proposed by Mozdianfard and Behranvand ${ }^{34}$ ). Inorganic deposition and its promoting effect on organic deposition are regarded here as a disturbance to the system. The additional organic deposition rate due to the presence of inorganics $\left(n_{f, o r g, i / o}\right)$ is also assumed to be proportional to the deposition rate of inorganics by means of a constant $p_{i / o}$, which is treated as an additional adjustable parameter, i.e.:

$$
n_{f, \text { org }}=n_{\text {ref }}+n_{f, \text { org }, i / o}=n_{\text {ref }}+p_{i / o} \rho_{\text {org }} \frac{n_{f, \text { inorg }}}{\rho_{\text {inorg }}} ; \quad p_{\text {inorg }}=p_{\text {inorg }}(t)
$$

\section{CASE STUDY: THERMO-HYDRAULIC ANALYSIS OF FOULING RATE}

The industrial case study focuses on the 2-shells, multiple passes, shell and tube PDPF exchanger E155AB in the field study conducted by Mozdianfard and Behranvand ${ }^{34,51}$. Desalting performance, water injection, brine chloride hydrolysis, caustic injection, asphaltenes solubility dependence on 
temperature variation, and its molecular structure as a surfactant agent were identified as effective factors contributing to deposition of severe, tenacious and stable foulant on the tube surfaces. The main step of a special mechanism proposed for this combined fouling of organic and inorganic matter was the formation of insoluble associations of $\mathrm{CaCO}_{3}$ compounds surrounded by asphaltene molecules on which iron sulphide particulates are adsorbed. Background information on the case study is also reported elsewhere. ${ }^{7,34}$. Plant data available for the study include measurements of tubeside pressure drop, temperature and flowrate measurements over about four years (1256 days) of operation. At the end of the period, the exchanger was dismantled, some tubes cut open and the tubeside deposit measured and analysed, as described in ref. .

\section{Apparent fouling rate and Inorganic-to-organic ratio}

In this section, results from the data-driven analysis of fouling state presented in ref. ${ }^{7}$ are used to calculate the tube-side apparent fouling rate and the inorganic-to-organic ratio over time, aiming to identify how fouling built up on the tube-side of E155AB and the potential relationships between deposition rate, presence of inorganics and various operating conditions.

An apparent net deposition rate $\left(d \delta_{d} / d t\right)$ is hence calculated as the first derivative with respect to time of the apparent thickness time profile (Figure 1). Such net deposition rate is shown in Figure 3(a) for the entire four years of operation. Due to scattering of the data, a 40-days moving average was used to visualize the underlying trend, shown as a continuous line in Figure 3a. It is worth noting that this fouling rate was calculated based on the apparent deposit thickness, estimated using tube-side pressure drops. Therefore, it can be directly interpreted as a deposition rate, as opposed to the usual indirect approach, based on thermal fouling resistances. This deposition rate is not by any mean a monotonic decaying function; it contains several peaks when the fouling layer grows more rapidly (indicated with arrows at the top of Figure 3), with periods in between fluctuating around zero. The main peak marked with Arrow 2 corresponds to the main acute fouling episode observed in the apparent thickness profile in Figure 1. If peaks are ignored, a weak overall decreasing trend may be distinguished. We conjectured that these peaks could be related to inorganic breakthrough from the desalter, however insufficient records were available in the plant for this to be unequivocally 
confirmed by the operators. Several analyses that help infer the nature of the peaks are presented in the following.

The inorganic-to-organic deposition rate proportionality ratio, $p_{\text {inorg }}$, was calculated using Eq. 3, as explained in Section Modelling Framework. The results are shown in Figure 2(b) for the CC and EMT conductivity models, the two mixing models that presented the best agreement with the experimental analysis of the deposits. As observed in Figure 2(a), the concentration profile is not uniform through the layer. In particular, there is a portion of deposit with very high inorganic content between 0.8-1.5 $\mathrm{mm}$ from the tube wall surface. Other two smaller portions of the deposit with high inorganic content are also observed at about $0.5 \mathrm{~mm}$ and $2.3 \mathrm{~mm}$ from the tube wall. The choice of conductivity model has a strong impact on the calculated relative deposition rate ratio, as each model gives different weight to the larger conductivity of the inorganic fraction. However, both models identify peaks in the same positions. In a refinery environment, the sensitivity of the deposition rate ratio would be important to detect low levels of inorganics. A better resolution in the choice of model could possibly be achieved by analysis of deposit carefully obtained in controlled laboratory conditions.

As discussed earlier, the local composition, hence the local pinorg, at each deposit depth is a consequence of the relative deposition rate of inorganics and organics at the time when that deposit is settled. Using the tracking capabilities of the deposit model (Table 1), the final radial profile of $p_{\text {inorg }}$ can be transformed into a time profile, providing information on the inorganic-to-organic deposition ratio, as fouling is built-up. Figure 3(b) shows the time profiles of the inorganic-to-organic deposition rate ratio obtained with the EMT and CC models. The figure evidences a main and other two secondary peaks of $p_{\text {inorg }}$, which correspond to the three sub-layers of deposit presenting high inorganic content, mentioned above. A comparison of the results with the apparent deposition rate profile (Figure 3a) shows that the maxima in deposition rate overlaps clearly with inorganicdominated deposition periods. Therefore, alternate acute deposition of inorganic salts and chronic organic/inorganic deposition may reasonably be identified as the underlying fouling mechanisms.

The causes leading to acute inorganic deposition might therefore be related to high concentration of inorganic particles or precursors associated with several underlying factors mentioned above. The only information available in that regard was the salt content in the oil leaving the desalter and 
entering the exchangers, which was measured once or twice a week during the operating period. These salt content measurements, accounting for such ions as $\mathrm{Na}, \mathrm{Ca}$ or $\mathrm{Mg}$ (species such as $\mathrm{Fe}$ are not accounted for) are plotted in Figure 3(c) as a moving average based on 5 data points (continuous line, together with measured points with statistically significant high salt content - above the $95 \%$ confidence interval). These points are significant, as the corresponding 3-4 days period with very high salt concentration could be the cause of acute fouling. Again, peaks in the salt content moving average and points with significantly high salt content seem to broadly overlap with those in the calculated deposition rate. At the time of the greatest fouling rate peak (arrow 2), however, salt content does not show significantly higher values compared to the others. Therefore, these results do not conclusively indicate direct influence of salt content on the deposition rate and hence, more regular measurements (perhaps daily) of salt, rate of injected water and caustic, and where possible Fe and S contents could be useful.

Other factors taken into consideration are the calculated wall shear stress and film temperature under fouled conditions (accounting for the deposit thickness), shown in Figure 3(d, e) for the entire operating period. Shear stress increases over time due to the increase in deposit thickness. Ignoring the peaks, the increasing trend in shear stress may explain the underlying weakly declining trend in the fouling rate, as this is consistent with the inverse relationship between those two variables in typical crude oil fouling correlations (e.g. Eq. 4). However, the shear stress profile does not show any special features (e.g. very low values) during the fast deposition periods that could explain such changes in behaviour. On the other hand, the later increase in shear stress could well explain the progressively smaller intensity of the acute deposition episodes, particularly after Arrow 2: during the initial stages, the tube is relatively clean, shear stress is relatively low and deposition is facilitated; as deposit builds up, shear stress increases, which could limit deposition either by suppression or removal ${ }^{25}$.

Temperature is also likely to play an important role in the deposition rate of organics (e.g. in asphaltene solubility) and some inorganic salts (e.g. in brine chloride hydrolysis). However, as for shear stress, no special temperature condition was detected, by visualizing the data series during the fast deposition periods, which could explain such changes in behaviour as illustrated in Figure 3(e). 
Finally, particle attachment also depends on the type of surface and its mechanical properties. The state of the tube wall surface (roughness, corrosion) is likely to influence heavily the initial stages of deposition.

\section{Step ii-1 - Selection of deposition model}

Based on the above analysis, four stages or sub-periods are identified:

i) initial development of the deposit layer with intermediate content of inorganics;

ii) acute deposition of inorganic particles (indicated by arrow No. 2 in Figure 3);

iii) intermediate stage (from arrow 2 to arrow 3 in Figure 3), during which deposition of salts correlates well with salt content, however high shear stress begins to limit deposition;

iv) final period (after arrow 3 in Figure 3), during which the high shear stress reduces significantly salts deposition, and chronic organic fouling seems to be the main mechanism.

The results indicate clearly that deposition rates of organic and inorganic foulants depend differently on operating conditions (e.g. temperature, shear stress, concentration of precursors). This may involve various underlying processes:

a) Single combined organic-inorganic deposition mechanism (e.g. as in ${ }^{34}$ ), but with organic and inorganic species having different propensity to removal by shear stress (i.e. inorganic particles are removed more easily at high shear stress). Such "replenishment" of fouling deposits has proven to occur in other industrial systems (e.g. ${ }^{52}$ ).

b) Multiple concurrent fouling mechanisms including those responsible for individual organic (e.g. chemical reaction fouling ${ }^{21}$ ), inorganic fouling (e.g. particulate fouling ${ }^{53,54}$ ), or combined organic-inorganic mechanism (e.g. ${ }^{34}$ ), depending to different extent on operating conditions.

The results indicate that, out of the deposition rate configurations proposed in Section Deposition rate model for mixed inorganic-organic deposition, the system is better described by those with timevarying $p_{\text {inorg }}$ (Eqs. 6,7). This is explored in the next section, where all proposed configurations are tested against plant data for the same heat exchanger. 


\section{Step ii-2. Estimation of fouling parameters}

The unknown parameters in each of the selected deposition rate models are estimated using the advanced parameter estimation facility, based on the Maximum Likelihood approach (MAXLKHD solver), available in the solution platform ${ }^{55}$ underlying Hexxcell Studio. Before presenting the results, some preliminary notes on the procedure are needed.

First, the baseline deposition model (Eq. 4) involves three unknown parameters $\left(\alpha^{\prime}, E_{f}, \gamma^{\prime}\right)$. The Arrhenius formulation in Eq. 4 was rearranged to its linear form to reduce the correlation between pre-exponential factor and activation energy ${ }^{56}$. Despite this, $\alpha^{\prime}$ and $E_{f}$ were still found to be highly correlated, hence, $E_{f}$ was fixed to a typical value of $28.5 \mathrm{~kJ} / \mathrm{mol}\left({ }^{14,26,42}\right)$ in order to reduce the overparameterization of the system, and only $\alpha^{\prime}$ and $\gamma^{\prime}$ were estimated.

Second, the fouling parameters estimation was performed by fitting the full dynamic, 2D distributed model to tube-side pressure drop measurements, instead of temperatures. The reasons for this are:

a. Tube-side pressure drop measurements were provided throughout the operating period, which are independent of those on the shell-side. An analysis of the measurement variability led to a constant variance model with $\sigma=0.22$ bar.

b. Thermal measurements (exit temperatures) are implicitly used by selecting the proportionality constant. They were used to check the goodness of fit rather than estimating the fouling parameters.

Temperatures, flowrates and pressure drop measurements were taken as the measured daily values. A preliminary analysis is first provided below in which the composition of the deposit is ignored and a classic assumption on the nature of the deposit as organic is made, to enable a comparison with past approaches. Then, the effect of mixed inorganic-organic composition is introduced, gradually increasing complexity in the inorganic-to-organic deposition rate proportionality ratio. 


\section{Preliminary study: Uniform deposit with assumed deposit's conductivity (Case 0)}

When pressure drop data are unavailable, analysis of fouling rates is typically performed based on temperature measurements alone. Traditional approaches use lumped fouling resistances (averaged overall for an entire exchanger) to fit fouling models, while disregarding flow area constriction and any associated hydraulic effect. Once a thermal resistance has been estimated, by selecting a deposit thermal conductivity, it is possible to translate the thermal resistance into a deposit depth and hence, an estimate of pressure drops. If the assumed conductivity is incorrect, it will not be possible to capture both thermal and hydraulic impacts of fouling. In more advanced methods, such as that suggested by ref. ${ }^{42}$, the distribution and thickness of the deposit layer are accounted for, having assumed an organic deposit undergoing ageing. This assumption, however, relies on the common belief that chemical reaction fouling is the main deposition mechanism. A methodology that uses pressure drop predictions as a soft-sensor to narrow down the range of feasible conductivities was proposed ${ }^{26}$. Whilst this method allows establishing a maximum feasible deposit conductivity, it has limited capabilities in determining the conductivity with some precision, especially if the thermal impact of fouling is not severe. The case study in ${ }^{26}$ still assumed a fully organic deposit. However, as in the case study presented here, the deposit may contain significant amounts of inorganics.

First, the potential error is established in the pressure drops predicted when temperatures alone, or pressure drops alone, are used to fit fouling models in isolation, with this organic assumption. Typically, it is assumed that a deposit is only composed of organic material $\left(p_{\text {inorg }}=0\right)$ with a standard literature conductivity, $\lambda_{l}=0.2 \mathrm{Wm}^{-1} \mathrm{~K}^{-1}$, at all times (organic deposit, with no ageing). Two cases are presented: fouling parameters fitted to temperature measurements (the usual approach, labelled Case 0T), and fitted to pressure drop measurements (labelled Case 0P).

a) Organic deposit and model fitted to temperature measurements (Case OT)

Estimation of the fouling parameters was carried out using the tube-side outlet temperatures as measurements. Results (Figure 4) indicate good agreement between predicted and measured outlet temperatures, as expected. The predicted pressure drops, however, diverge significantly from the measurements. At the end of the period, the difference is in excess of $2.2 \mathrm{bar}$, that is, the predicted 
pressure drop is only about one half of the measured one. This confirms that, in the absence of pressure drop measurements, the standard methodology assuming an organic deposit could be applied successfully to fit the thermal data. However, the pressure drop would have been highly underpredicted, leading to considerably wrong results if used as a basis for design or operating decisions.

\section{b) Organic deposit and model fitted to $\triangle P$ measurements (Case OP)}

Similarly, estimation of the fouling parameter was performed using the pressure drop measurements, assuming an organic deposit. As can be seen from the overlay chart in Figure 5, the trend in $\Delta P$ is generally well captured, although with some disagreement during the peaks in pressure drop starting from day 150 (corresponding to the peak in the main deposition rate identified with arrow 2 in Figure 3a). However, the predicted outlet temperature is significantly lower than that predicted using the average apparent conductivity. The residual varies between about $24^{\circ} \mathrm{C}$ (maximum value) to about $10^{\circ} \mathrm{C}$ at the end of the period. Thus, assuming a typical organic deposit lead to significant deviations in the prediction of thermal performance. The importance of this deviation should be evaluated in the context of the large costs associated with a drop in the inlet temperature at the furnace: a $1^{\circ} \mathrm{C}$ drop is worth approximately $£ 0.25 \mathrm{M}$ per annum for a $100,000 \mathrm{bbl}$ per annum refinery ${ }^{42}$.

These results confirm the need for taking into account proper conductivity estimates that account for the presence of inorganics, so as to capture the impact of fouling on both thermal and hydraulic heat exchanger performance, as shown in the next sections.

\section{Uniform mixture approximation (Case A)}

In this section, the presence of inorganics is accounted for by considering the increased conductivity they cause. However, the deposit is still assumed to have a uniform composition (hence, conductivity). The fouling rate is described according to the relative deposition model (1) (Eq. 5). The deposit conductivity is assumed to be the average apparent thermal-conductivity of the deposit, found to be $0.93 \mathrm{Wm}^{-1} \mathrm{~K}^{-1}$ in the analysis of deposit state for the same exchanger presented in ${ }^{7}$. This average conductivity represents a mixture with $48.9_{\mathrm{wt}} \%$ and $47.9_{\mathrm{wt}} \%$ of inorganic matter, calculated with the CC and EMT conductivity model, respectively, and with the inorganics thermal conductivity 
$\lambda_{l}=4 \mathrm{Wm}^{-1} \mathrm{~K}^{-1}$. The ratio $p_{\text {inorg }}$ is constant and equal to 0.71 and 0.68 for the $\mathrm{CC}$ and EMT models, respectively. That is, the deposition rate of the inorganic foulant is about $70 \%$ that of the organic foulant at all times.

The estimation of the unknown parameters was performed using pressure drop measurements, and results are shown in Table 2 (Case A). The lack-of-fit and t-test were both passed, indicating good fit and confidence in the estimates obtained, although there is still a strong correlation between $\alpha^{\prime}$ and $\gamma^{\prime}$. The trend in $\Delta P$ (Figure 6a) is generally well followed. The residuals (Figure 6b) show that the pressure drop is fitted within the measurement error $( \pm 0.2$ bar) for most of the time. The greatest disagreement coincides with the pressure drop peak (arrow 2 in Figure 3a), where the maximum residual is -0.8 bar. This was expected, since no special conditions of temperature or shear stress (the operating conditions accounted for by the Ebert-Panchal correlation, Eq. 4) are observed in the data during that period. The model compensates for the errors in the acute deposition period with high values of $\alpha^{\prime}$ and $\gamma^{\prime}$, resulting in a falling rate shape, with marked curvature in the deposit thickness profile (Figure 7a).

Using a 2D distributed exchanger model, the deposit thickness is also distributed (i.e., not uniform) along the heat exchanger, as a result of deposition rates dependence on the local operating conditions. Figure 7(a) shows the evolution over time of the average deposit thickness for each of the 2 shells and average for the exchanger as a whole. This model does not capture the acute deposition phase after day 150 and the following plateau in the apparent thickness (between days 200 and 350). Otherwise, the overall trend of the apparent thickness is followed well by the simulated one. Fouling in the E155A exchanger (the hottest shell) builds up faster than in E155B, which can be attributed to the temperature dependence imposed by Eq. (4), and also exhibits a falling-rate behaviour at an earlier time. At the end of the operating period, the deposit thickness is similar in both shells $(2.9 \mathrm{~mm}$ and 2.6 $\mathrm{mm}$ for E155A and E155B, respectively). Although the final extent of tube blockage is similar, most deposit in E155A had been formed at an earlier stage than in the E155B exchanger. This deposit model allows tracking the deposit age history (the time elapsed from deposition to the present time for every portion of the deposit). The age radial profile at the end of the investigated period (1256 days) is shown in Figure 7(b) for the deposit at the entrance of E155B (its coldest end) and the exit of E155A 
(its hottest end). Layers of deposit located at the same distance from the wall are older in E155A than in E155B, since they were deposited earlier in time. For instance, the deposit located $2.2 \mathrm{~mm}$ from the tube surface (indicated with dashed-dotted line in the figure) is 412 days old at the entrance of E155B, but 897 days old at the exit of E155A (almost twice the age). The visual difference between the deposits scraped from the two exchangers, shown in Figure 8, may be explained by variations in the deposit age, temperature and inorganic content.

The tube-side outlet temperature predicted by this model is shown in Figure 9(a). The outlet temperature is generally under-predicted when the assumed average conductivity is lower than the apparent one $\left(\lambda_{a v e}<\lambda_{a}\right)$, and over-predicted otherwise. This expected trend, however, changes during the acute deposition period: the thickness is significantly underestimated and, as a result, the heat duty and tube outlet temperature are over-estimated. A clearer visualization is provided by the outlet temperature residuals in Figure 9(b). Despite missing the acute deposition period, a satisfactory prediction of the outlet temperature is achieved, within $\pm 4^{\circ} \mathrm{C}( \pm 2.5 \%)$ at the end of the period. Therefore, inclusion of the conductivity enhancement effects due to inorganics allows capturing the decay in both thermal and hydraulic performance, as opposed to the previous Case 0 .

This deposition model broadly captures the thickness trend over time and could hence be used to provide a reasonable prediction of the unit performance, as long as similar operating conditions are maintained. However, it is insensitive to changes in concentration of salts or other precursors that can influence the system significantly. The implicit assumption, if the model is used for prediction, is that the acute inorganic episodes will happen in a similar fashion in future operations.

\section{Time-varying inorganic-to-organic deposition ratio with independent mechanisms (Cases B, C)}

Here the relative deposition model (2) in Eq. 6 is adopted. The rate of inorganic deposition is assumed to be proportional to the organic deposition rate according to the time-varying proportionality ratio $p_{\text {inorg }}$, the values of which were calculated in Section Apparent fouling rate and Inorganic-to-organic ratio. The same two parameters as before $\left(\alpha^{\prime}\right.$ and $\left.\gamma^{\prime}\right)$ were fitted to measured data with the EMT (Case B) and CC (Case C) models (Figure 3b). Results, presented in Table 2 (Case B, 
C), indicate a satisfactory statistical analysis, as before. Both lack-of-fit and t-test were met, but with strong correlation between parameters $\alpha^{\prime}$ and $\gamma^{\prime}$. According to the lack-of-fit test, a better fit is achieved with the CC model. This is clearly observed in the corresponding pressure drop overlay charts (Figure 10a, b) and residuals (Figure 10c, d). As with the uniform model (Case A), the residuals show that the fitted pressure drop is within the measurement error $( \pm 0.2$ bar $)$ most of the time. In contrast to Case A, the peak in pressure drop is partially captured, as a result of the variable inorganicto-organic rate ratio. With EMT, only a slight improvement is achieved with respect to the uniform model (the maximum residual is -0.7 bar compared to the previous one of -0.8 bar). In Case $\mathrm{C}$, the improvement is substantial, reducing the maximum residuals to \pm 0.5 bar throughout the 4 years of operation (including the period corresponding to the pressure drop peak). As the pressure drop peak is better captured, the organic deposition model results in lower values of parameters $\alpha^{\prime}-\gamma^{\prime}$, since a less marked curvature in the deposit thickness time profile is required to fit the data.

As before, the model provides the distributed deposit thickness and outlet tube temperature. The average deposit thickness for each shell independently and for the unit as a whole are shown in Figure 11(a, b). The apparent thickness is followed much better in Case C, as expected, in view of the pressure drop results, with values falling within the error bars for most of the operation period. As before, the deposit in E155A grows faster than in E155B but the final thickness is similar in both shells. The difference in fouling rate is substantial in the acute fouling period and leads to greater overall inorganic content in E155A at the end of the period. This is consistent with the experimental deposit analysis results reported in ref. ${ }^{7}$

The predicted vs. measured tube-side outlet temperature and the corresponding residuals are shown in Figure 12(a-d). The results in Case B are similar to those in Case A during the first half of the period but significantly improved towards the end. During the acute deposition period, the pressure drop is captured better in Case B than Case A but is still under-predicted. The higher deposit thermal-conductivity in Case B during that period compensates for the greater deposit thickness and leads to the same residuals in the predicted outlet temperature. In Case $\mathrm{C}$, the prediction shows excellent agreement with the measured outlet temperature after the acute deposition period $\left( \pm 3^{\circ} \mathrm{C}, \approx\right.$ 
$\pm 2 \%$ ). Before that, the under-estimation of the deposit thickness, together with the higher conductivity, lead to similar residuals to those in Cases A and B.

To highlight the effect of the deposition ratio model, Figure 13(a) illustrates the average organic deposition rate and average total deposition rate in Case B. The organic deposition rate (continuous line), which follows the Ebert-Panchal formulation with the estimated parameters (Eq. 4), shows an overall monotonic decreasing trend, with small fluctuations that depend only upon variations in shear stress and/or film temperature. In addition to the organic deposition, the inorganics build up according to the time variable value of the proportionality coefficient, $p_{\text {inorg. }}$. The overall contribution of the two components (dashed line) gives a total deposition rate that presents an overall decreasing trend, but includes some episodes of acute deposition. Such time profile compares well with the apparent deposition rate, as shown in Figure 13(b), which also demonstrates convincingly that an EbertPanchal type formulation alone (Case A) cannot capture the apparent deposition rate, as it does not account for factors other than temperature and shear. Case B (EMT) underestimates the acute deposition period, whilst CC captures the acute episodes more accurately.

The above results show that Case $\mathrm{C}(\mathrm{CC})$ provides a more accurate description of the thermohydraulic impact of fouling on E155AB, with larger inorganic-to-organic ratio in the acute inorganic deposition periods explaining the same local conductivity. The deposit composition predicted by the CC model, seems to support the assumption made in this section, that the organic material deposits at a rate that is independent of the inorganic behaviour. This explains the better fit in this case but does not imply a general validation of the $\mathrm{CC}$ model in describing crude oil fouling. Further experimental data linking deposit conductivity to composition is clearly required, in particular in more controlled laboratory conditions, or by measuring the conductivity of an intact deposit sample on the surface where it was deposited.

The fact that the pressure drop peak is not completely captured, together with the consequent over-estimation of the exit temperature in that period for $\mathrm{CC}$, seems to indicate that the acute periods cannot be explained with deposition of inorganics alone, i.e. most likely there is a reinforcing relationship between inorganic and organic deposition, which is explored in the next section. Moreover, it should be noted that the imposed evolution of the local conductivity is subject to the 
uncertainty inherited from the deposit state analysis of the primary thermal-hydraulic measurements, especially during the initial stages, and it is certainly responsible for part of the deviation in the outlet temperature prediction.

\section{Time-varying inorganic-to-organic ratio with reinforcing interaction (Cases D, E)}

Here the relative deposition model (3) in Eq. 7 is adopted. As in the previous section, the inorganic pseudo-component deposition rate is assumed to be proportional to the organic deposition rate according to the $p_{\text {inorg }}$ time profile, obtained with the EMT (Case D) and CC (Case E) models (Figure $3 b$ ). The same parameter estimation procedure was applied with the addition of the extra fitting parameter, $p_{i / o}$, introduced in Eq. 7 , representing the organic deposition rate enhancement caused by inorganics. The results of the parameter estimation are shown in Table 2 (Case D, E). As for cases $\mathrm{B}$ and $\mathrm{C}$ above, both lack-of-fit and t-test were met, but with strong correlation between the parameters. With EMT (Case D), the results significantly improve compared to Case B. Figure 14 shows the overlay chart for the tube-side pressure drop (a) and outlet temperature (b) and the corresponding residuals (c, d), for Case D. Here, the peak in pressure drop is partly captured and the quality of the fitting is comparable to that obtained with the $\mathrm{CC}$ model (both in Cases $\mathrm{C}$ and $\mathrm{E}$ ). The predicted tube-side outlet temperatures and corresponding residuals are similar to those obtained in Case C. In Case D, the optimal estimate of the new parameter, $p_{i / o}$, is 0.24 (i.e. 24\%). That is, for each unit of inorganics that is deposited (on volume basis), 0.24 units of organic material deposits in addition to the amount predicted by the baseline organic deposition model (Ebert-Panchal formulation). This indicates a significant reinforcing effect on the organic deposition.

With CC (Case E), the fitted $p_{i / o}$ is very small $(1.3 \%)$ and is the only parameter that did not pass the t-test (Table 2). This seems to indicate that $p_{i / o}$ could be fixed to 0 and the reinforcing effect could be neglected without a significant impact on the results. Indeed, the fitted pressure drop is essentially the same as in Case $\mathrm{C}$, as indicated by the residuals in the lack-of-fit test, leading very similar prediction of the outlet temperature (the time profiles are not shown). According to this model the deposition of inorganics barely reinforces the organic deposition. 
Figure 15(a) shows the average organic deposition rate predicted by the baseline model (black continuous line), the total organic deposition rate (baseline plus inorganic-promoted - grey continuous line) and the total deposition rate (organics plus inorganics -dashed line), in Case D. As before, the organic deposition rate predicted by the Ebert-Panchal formulation (with the estimated parameters), shows an overall monotonic decreasing trend. In addition to the organics baseline, the inorganics build up proportionally according to the time-varying proportionality ratio, $p_{\text {inorg, }}$ and promotes a certain amount of additional organic deposition according to $p_{i / /}$. As a result, the overall organic deposition rate presents peaks that stand out from the underlying decreasing trend. The overall contribution of the two pseudo-components results in a total deposition rate that compares well with the apparent deposition rate, as shown in Figure 15(b). Differently from the previous section, the acute deposition rates are well represented by the combined organic and inorganic deposition.

Figure 15(b) shows that Case D, which uses EMT and presents significant inorganic reinforcement effect, and Case E, which uses CC and presents negligible reinforcement effect, predict a very similar total deposition rate that seems to capture with reasonable accuracy the acute deposition episodes in the apparent rate moving average.

Differently from the previous models, the perturbation from the organic baseline is due to deposition of inorganic-organic mixtures according to the estimated proportion, which is assumed to be constant. Although further understanding of the reinforcing relationships between various deposition mechanisms is required, these models represent an initial effort to capture and quantify such effect and introduce it into a fouling monitoring and analysis strategy. The approach is more realistic than previous models, which considered independent inorganic and organic deposition, and agrees better with observations in experimental studies. Nevertheless, if the reinforcing effect is small (as in Case E) it can be neglected and a model of the type in Eq. 6 is sufficient to represent the system. As before, further work is required to establish reliable structural conductivity models for crude oil deposits. 


\section{DISCUSSION}

The fouling rate in a refinery heat exchanger undergoing a combined inorganic-organic deposition has been successfully analysed. Various relative deposition rate models have been proposed and fitted using flowrate, temperature and pressure drop plant measurements over a period of nearly four years, with excellent results.

A preliminary analysis of the apparent net overall deposition rate showed that a non-monotonic, but generally decreasing, trend, with several peaks along the operating period corresponded well to some high conductivity deposit layers. These results supported an interpretation of alternate periods of slow chronic fouling (with predominant content of organic material) and acute fouling periods with fast salt deposition. Based on these results, the deposition history over the 4 years of operation was reconstructed. It was concluded that the succession of key events included: i) an initial period of mixed inorganic (with moderate content) and organic deposition; ii) a short period of acute fouling with high inorganic content; iii) a slow fouling deposition, due to high shear, with increasing proportion of organic matter and some short periods of faster (but less severe than in ii) inorganic fouling.

The results presented here indicate that the proportionality ratio approach, initially suggested in a simulation study in ref. ${ }^{24}$ to model the mixed inorganic-organic deposition rate, works well in practice with typical plant data. A baseline for the organic deposition rate is first calculated, for which a version of the Ebert-Panchal model was assumed. The inorganic deposition is then regarded as a disturbance from that baseline and assumed to follow a proportionality ratio, which was extracted from the dynamic analysis of fouling state presented in ref. ${ }^{7}$ The approach presented in ref. ${ }^{24}$ was extended here to incorporate a series of organic/inorganic deposition models of increasing sophistication. These progressively introduced more degrees of freedom (in mathematical terms) enabling the incorporation (in physical terms) of more complex interactions between organic and inorganics deposition rates. Only the adjustable parameters in the Ebert-Panchal correlation (i.e. the baseline organic deposition rate parameters) were fitted to the plant data. An advantage of this approach is that it permits fitting a deposition rate for inorganic-organic mixtures that only depends on 
temperature and shear stress and does not require additional information such as concentration of fouling precursors in the bulk of the oil stream. It was also shown that models which assume organics deposition on their own, on the other hand, have limited prediction capabilities, while including a "disturbance" from such baseline due to inorganics leads to good fit and predictions of both thermal and hydraulic data. Estimation of fouling parameters was performed by fitting the model to pressure drop data rather than the commonly used thermal information. Temperatures were used to assess and validate the model predictions.

First, it was shown that neglecting deposit composition and estimating fouling parameters from purely thermal data, as is traditionally done, while assuming a typical organic deposit $\left(0.2 \mathrm{Wm}^{-1} \mathrm{~K}^{-1}\right)$ resulted in evident failure to simultaneously capture the decay in thermal and hydraulic performance. The deposit was then assumed to be a uniform organic-inorganic mixture with constant, but greater, conductivity. This model provided a good fit of the pressure drop and a reasonably good prediction of the tube outlet temperature. Results demonstrate the need for considering the increased conductivity due to the presence of inorganics in order to explain the decay in both thermal and hydraulic performance as fouling builds-up. However, this deposition model could not capture the acute deposition period, as expected, since the resulting deposition rates do not take into account crude oil composition effects.

The use of a time-varying inorganic-organic deposition proportionality ratio $\left(p_{\text {inorg }}\right)$, obtained from an independent, data driven dynamic fouling state analysis, enabled capturing different fouling propensity of organic and inorganic species over time. Two alternative hypotheses, proposed in the literature, were tested whereby the organic deposition rate is either independent of the presence of inorganics or is reinforced by it. The first hypothesis (relative deposition model 2) could represent deposition mechanisms related to factors such as desalting performance, water injection, brine chloride hydrolysis, caustic injection, and asphaltenes solubility. The second hypothesis (relative deposition model 3), could represent additional reinforcing interactions on the overall organic deposition rate arising, for example, by the effect of formation of insoluble associations (e.g. $\mathrm{CaCO}_{3}$ surrounded by asphaltene molecules). The case study showed that both these models could substantially capture the acute deposition periods of a problematic exchanger over a four-year period 
of operation, providing an excellent fit of the pressure drop data and prediction of thermal performance over the entire period. Further fundamental work is necessary to clarify if and to which extent there is a reinforcement interaction between organic and inorganic deposition. Nevertheless, the approach presented permits taking into account such effects, described in experimental studies, in a pragmatic way.

Access to good quality temperature and pressure drop measurements is needed in order to exploit this integrated data and model-based analysis approach to crude oil fouling monitoring. Pressure drop measurement are not always available, but their addition has been recognised in industry as being very useful ${ }^{57}$. Resolution between alternative structural conductivity models for crude oil deposits and development of more precise deposition models from mixed organic/inorganic crudes (and role of salts) would also be a useful addition. It is suggested that these activities should be carried out in well designed and controlled laboratory experiments.

\section{CONCLUSIONS}

A framework and methodology for plant data analysis ${ }^{26}$ was applied to an industrial case study of a heat exchanger located in between the desalter and the flash dram of a refinery preheat train. The framework was extended to include various relative deposition rate models. This paper focused on the analysis of fouling rates and the results built on a previous analysis of the fouling state ${ }^{7}$. All results were obtained from analysis of a set of operating data of typical extent and quality, comprising pressure drop measurements across the exchanger, in addition to flowrate and temperature.

An analysis of the apparent deposition rates led to the following conclusions:

1. Fouling seemed to follow alternate periods of slow chronic fouling (mostly organic) and fast salt deposition. This was well identified using a time-varying inorganic-to-organic proportionality ratio.

2. The inorganic deposition could be related to inorganics breakthrough from the desalter at particular periods. However, the data available were not sufficient to unequivocally verify this hypothesis. The gradual lower intensity of these peaks could be related to the increasing shear stress as the deposit builds-up. 
Several relative deposition rate models were tested by fitting the models to pressure drop data and testing the predicted results against the measured outlet temperature, leading to the following conclusions:

1. A fouling model fitted to temperatures with a typical assumption on the thermal-conductivity of crude oil deposits (as is the current practice) would lead to a significant underestimation of the pressure drop.

2. The decay in both thermal and hydraulic performance could only be captured when considering the increased conductivity due to the presence of inorganics (obtained in the preliminary analysis of the fouling state).

3. The imposition of a time-varying inorganic-to-organic deposition ratio, obtained from plant data, results in an improved fitting of the pressure drop, capturing well the acute fouling periods.

4. The resulting model predicts the chronic organic fouling baseline and detects inorganic deposition as a perturbation from that baseline.

The introduction of composition (as aggregate organic and inorganic pseudo-components) into the description of the crude oil fouling deposition rates, including reinforcing effects, and the use of pressure drop measurements to fit such models are, to the authors' knowledge, novel contributions to the literature.

The approach presented represents a highly promising new way to combine advanced deterministic thermo-hydraulic models and data driven analysis in monitoring fouling and supporting the development of soft-sensors for early detection of inorganics. It allows decoupling organic fouling from inorganic acute deposition, which often have very similar effects on thermal performance. The method may be used to predict the base-line deposition of organic material and then monitor, by comparison with properly analysed thermo-hydraulic plant measurements, the amount of inorganics that may also be depositing at each time. That is, inorganic deposition is viewed as a perturbation from a reliably predicted base line. This allows an early detection of acute deposition periods, an early diagnosis of the likely causes and supports remedial decision making. 


\section{ACKNOWLEDGMENTS}

Initial methodological aspects of this research were partially performed under the UNIHEAT project, for which EDB and SM wish to acknowledge the Skolkovo Foundation and BP for financial support. EB and MRM wish to acknowledge EORC for the provision of case study data. Hexxcell Ltd. for the provision of Hexxcell Studio ${ }^{\mathrm{TM}}$ is also acknowledged.

\section{NOMENCLATURE}

$$
\begin{aligned}
& A \quad=\quad \text { Flow area, } \mathrm{m}^{2} \\
& c=\text { Mass concentration, } \mathrm{kg} \mathrm{m}^{-3} \\
& C C=\text { Co-continuous } \\
& C_{f} \quad=\text { Friction factor, }- \\
& C_{p} \quad=\quad \text { Specific heat capacity, } \mathrm{J} \mathrm{kg}^{-1} \mathrm{~K}^{-1} \\
& \text { dir }=\text { Direction of flow, }- \\
& E_{f} \quad=\text { Fouling deposition activation energy, } \mathrm{J} \mathrm{mol}^{-1} \\
& E M T=\text { Effective media theory } \\
& h=\text { Heat transfer coefficient, } \mathrm{J} \mathrm{m}^{2} \mathrm{~K}^{-1} \\
& H \quad=\quad \text { Specific enthalpy, } \mathrm{J} \mathrm{kg}^{-1} \\
& L=\text { Tube length, } \mathrm{m} \\
& \dot{m}=\text { Mass flowrate, } \mathrm{kg} \mathrm{s}^{-1} \\
& n_{f, i}=\text { Fouling rate of component } \mathrm{i}, \mathrm{kg} \mathrm{m}^{-2} \mathrm{~s}^{-1} \\
& N C=\text { Number of components } \\
& N_{p} \quad=\quad \text { Number of tube passes } \\
& N R=\text { Number of reactions } \\
& p \quad=\text { Perimeter, } \mathrm{m} \\
& P \quad=\text { Pressure, } \mathrm{Pa} \\
& P D P F \quad=\text { Post-desalter pre-flash drum } \\
& p_{\text {inorg }}=\text { Inorganic-to-organic deposition rate ratio of component } i \text {, - }
\end{aligned}
$$




$$
\begin{aligned}
& p_{i / o}=\text { Adjustable parameter, }- \\
& \operatorname{Pr} \quad=\text { Prandtl number } \\
& Q \quad=\text { Heat duty, } \mathrm{W} \\
& q^{\prime \prime} \quad=\text { Heat flux, } \mathrm{W} \mathrm{m}^{-2} \\
& R=\text { Tube radius, } \mathrm{m} \\
& R_{\text {flow }}=\text { Flow radius, } \mathrm{m} \\
& \text { Re }=\text { Reynolds number } \\
& R_{f} \quad=\text { Fouling resistance, } \mathrm{m}^{2} \mathrm{~K} \mathrm{~W}^{-1} \\
& R_{g} \quad=\quad \text { Ideal gas constant, } \mathrm{J} \mathrm{mol}^{-1} \mathrm{~K}^{-1} \\
& r \quad=\quad \text { Radial coordinate, } \mathrm{m} \\
& \tilde{r}=\text { Dimensionless radial coordinate, }- \\
& r_{j}=\text { Rate of reaction } \mathrm{j}, \mathrm{kg} \mathrm{m}^{-3} \mathrm{~s}^{-1} \\
& T=\text { Temperature, } \mathrm{K} \\
& T_{\text {film }}=\text { Tube-side film temperature, } \mathrm{K} \\
& t=\text { Time, } \mathrm{s} \\
& u=\text { Linear velocity, } \mathrm{m} \mathrm{s}^{-1} \\
& x=\text { Volume fraction, } \mathrm{m}^{3} \mathrm{~m}^{-3} \\
& z=\text { Axial coordinate, } \mathrm{m}
\end{aligned}
$$

\section{Greek letters}

$$
\begin{aligned}
\alpha^{\prime} & =\text { Deposition constant, } \mathrm{kg} \mathrm{m}^{-2} \mathrm{~s}^{-1} \\
\gamma^{\prime} & =\text { Removal constant, } \mathrm{kg} \mathrm{m}^{-2} \mathrm{~s}^{-1} \mathrm{~Pa}^{-1} \\
\Delta P & =\text { Pressure drop, } \mathrm{Pa} \\
\delta & =\text { Fouling layer thickness, } \mathrm{m} \\
\varepsilon & =\text { Error residual } \\
\rho & =\text { Density, } \mathrm{kg} \mathrm{m}^{-3} \\
\sigma & =\text { Standard deviation }
\end{aligned}
$$




$$
\begin{aligned}
\lambda & =\text { Thermal conductivity, } \mathrm{W} \mathrm{m}^{-1} \mathrm{~K}^{-1} \\
v_{i, j} & =\text { Stoichiometric coefficient for component } i \text { in reaction } j \\
\tau_{w} & =\text { Wall shear stress, } \mathrm{N} \mathrm{m}^{-2} \\
\Omega & =\text { Spatial domain }
\end{aligned}
$$

\section{Subscripts}

$$
\begin{aligned}
a & =\text { Apparent } \\
\text { ave } & =\text { Average } \\
\text { eff } & =\text { Effective } \\
f & =\text { Fouling } \\
i & =\text { Component number, inner radius } \\
\text { in } & =\text { Inlet } \\
\text { inorg } & =\text { Inorganic } \\
j & =\text { Reaction number } \\
l & =\text { Fouling layer } \\
o & =\text { Outer } \\
\text { org } & =\text { Organic } \\
\text { out } & =\text { Outlet } \\
\text { ref } & =\text { Reference } \\
t & =\text { Tube-side } \\
w & =\text { Shell-side } \\
w & \text { Tube wall } \\
&
\end{aligned}
$$

\section{REFERENCES}

(1) Macchietto S.; Hewitt G.F.; Coletti F.; Crittenden B.D.; Dugwell D.R.; Galindo A.; Jackson G.; Kandiyoti R.; Kazarian S.G.; Luckham P.F.; Matar O.K.; Millan-Agorio M.; Muller E.A.; Paterson W.; Pugh S.J.; Richardson S.M.; Wilson D.I. Fouling in Crude Oil Preheat Trains: A 
Systematic Solution to an Old Problem. Heat Transf Eng. 2011;32(3-4):197-215. doi:10.1080/01457632.2010.495579.

(2) Coletti F.; Joshi H.M.; Macchietto S.; Hewitt G.F. Introduction to Crude Oil Fouling. In: Coletti F.; Hewitt G.F., eds. Crude Oil Fouling: Deposit Characterization, Measurements, and Modeling. Boston: Gulf Professional Publishing (Elsevier); 2014.

(3) Müller-Steinhagen H.; Malayeri M.R.; Watkinson A.P. Heat Exchanger Fouling: Mitigation and Cleaning Strategies. Heat Transf Eng. 2011;32(3-4):189-196.

(4) Coletti F.; Macchietto S.; Refinery Pre-Heat Train Network Simulation Undergoing Fouling: Assessment of Energy Efficiency and Carbon Emissions. Heat Transf Eng. 2011;32(3-4):228236. doi:10.1080/01457632.2010.495606.

(5) Markowski M.; Trafczynski M.; Urbaniec K. Identification of the influence of fouling on the heat recovery in a network of shell and tube heat exchangers. Appl Energy. 2013;102:755-764. doi:10.1016/j.apenergy.2012.08.038.

(6) Costa A.L.H.; Tavares VBG.; Borges J.L.; Queiroz E.M.; Pellegrini Pessoa F.L.; Liporace F.S.; de Oliveira S.G. Parameter Estimation of Fouling. Heat Transf Eng. 2013;34(8-9):683691.

(7) Diaz-Bejarano E.; Behranvand E.; Coletti F.; Mozdianfard M.R.; Macchietto S. Organic and inorganic fouling in heat exchangers - Industrial case study: Analysis of fouling state. Appl Energy. 2017;206:1250-1266. doi:10.1016/j.apenergy.2017.10.018.

(8) Takemoto T.; Crittenden B.D.; Kolaczkowski S.T. Interpretation of fouling data in industrial shell and tube heat exchangers. Chem Eng Res Des. 1999;77(8):769-778.

(9) Crittenden B.D.; Kolaczkowski S.T.; Downey I.L. Fouling of Crude Oil Preheat Exchangers. Trans IChemE, Part A, Chem Eng Res Des. 1992;70:547-557.

(10) Coletti F.; Crittenden B.D.; Haslam A.J.; Hewitt G.F.; Jackson G.; Jimenez-Gutierrez G.; Macchietto S.; Matar O.K.; Müller E.A.; Sileri D.; and Yang J. Modelling of Fouling from Molecular to Plant Scale. In: Coletti F, Hewitt GF, eds. Crude Oil Fouling: Deposit Characterization, Measurements, and Modeling. Boston: Gulf Professional Publishing; 2014.

(11) Ebert W.A.; Panchal C.B. Analysis of Exxon crude-oil slip stream coking data. In: Panchal 
CB, ed. Fouling Mitigation of Industrial Heat-Exchange Equipment. San Luis Obispo, CA: Begell House; 1995:451-460.

(12) Panchal C.B.; Kuru W.C.; Liao C.F.; Ebert W.A.; Palen J.W. Threshold conditions for crude oil fouling. In: Bott T.R.; Melo L.F.; Panchal C.B.; Somerscales E.F.C., eds. Understanding Heat Exchanger Fouling and Its Mitigation. New York: Begell House; 1999:273-279.

(13) Nasr M.R.J.; Givi M.M. Modeling of crude oil fouling in preheat exchangers of refinery distillation units. Appl Therm Eng. 2006;26(14-15):1572-1577.

(14) Yeap B.L.; Wilson D.I.; Polley G.T.; Pugh S.J. Mitigation of crude oil refinery heat exchanger fouling through retrofits based on thermo-hydraulic fouling models. Chem Eng Res Des. 2004;82(A1):53-71.

(15) Polley G.T.; Wilson D.I.; Pugh S.J.; Petitjean E. Extraction of Crude Oil Fouling Model Parameters from Plant Exchanger Monitoring. Heat Transf Eng. 2007;28(3):185-192.

(16) Ratel M.; Kapoor Y.; Anxionnaz-Minvielle Z.; Seminel L.; Vinet B. Investigation of fouling rates in a heat exchanger using an innovative fouling rig. In: Malayeri M.R.; MüllerSteinhagen H.; Watkinson A.P, eds. Proc. Int. Conf. Heat Exchanger Fouling and Cleaning 2013. Budapest, Hungary; 2013:36-41.

(17) Deshannavar U.B.; Rafeen M.S.; Ramasamy M.; Subbarao D. Crude oil fouling a review. J Appl Sci. 2010;10(24):3167-3174.

(18) Wang Y.; Yuan Z.; Liang Y.; Xie Y.; Chen X.; Li X. A review of experimental measurement and prediction models of crude oil fouling rate in crude refinery preheat trains. Asia-Pacific $J$ Chem Eng. 2015;10:607-625.

(19) Wilson, D.I.; Ishiyama E.M.; Polley G.T. Twenty Years of Ebert and Panchal—What Next? Heat Transf Eng. 2017;38(7-8):669-680.

(20) Watkinson A.P. Critical Review of Organic Fluid Fouilng. Argonne, IL, USA; 1988.

(21) Watkinson A.P. Chemical Reaction Fouling of Organic Fluids. Chem. Eng. Technol. 1992;15(1 992):82-90.

(22) Ishiyama E.M.; Coletti F.; Macchietto S.; Paterson W.R.; Wilson D.I. Impact of Deposit Ageing on Thermal Fouling: Lumped Parameter Model. 2010;56(2):531-545. 
(23) Coletti F.; Ishiyama E.M.; Paterson W.R.; Wilson D.I.; Macchietto S. Impact of Deposit Aging and Surface Roughness on Thermal Fouling : Distributed Model. AIChE J. 2010;56(12):32573273. doi:10.1002/aic.

(24) Diaz-Bejarano E.; Coletti F.; Macchietto S. Impact of Complex Layering Structures of Organic and Inorganic Foulants on the Thermohydraulic Performance of a Single Heat Exchanger Tube: A Simulation Study. Ind Eng Chem Res. 2016;55(40). doi:10.1021/acs.iecr.6b02330.

(25) Diaz-Bejarano E.; Coletti F.; Macchietto S. Crude Oil Fouling Deposition, Suppression, Removal, and Consolidation—and How to Tell the Difference. Heat Transf Eng. 2017;38(78). doi:10.1080/01457632.2016.1206408.

(26) Diaz-Bejarano E.; Coletti F.; Macchietto S. Thermo-hydraulic analysis of refinery heat exchangers undergoing fouling. AIChE J. 2017;63(3). doi:10.1002/aic.15457.

(27) Diaz-Bejarano E.; Coletti F.; Macchietto S. A new dynamic model of crude oil fouling deposits and its application to the simulation of fouling-cleaning cycles. AIChE J. 2016;62(1). doi:10.1002/aic.15036.

(28) Srinivasan M.; Watkinson A.P. Fouling of Some Canadian Crude Oils. Heat Transf Eng. 2005;26(1):7-14.

(29) Bennett C.A.; Kistler R.S.; Nangia K.; Al-Ghawas W.; Al-Hajji N.; Al-Jemaz A. Observation of an Isokinetic Temperature and Compensation Effect for High-Temperature Crude Oil Fouling. Heat Transf Eng. 2009;30(10-11):794-804.

(30) Venditti S.; Berrueco C.; Alvarez P.; Morgan T.J.; Millan M.; Herod A.A.; Kandiyoti R. Developing Characterisation Methods for Foulants Deposited in Refinery Heat Exchangers. In: Müller-Steinhagen H, Malayeri MR, Watkinson AP, eds. International Conference on Heat Exchanger Fouling and Cleaning VIII. Schladming, Austria; 2009:44-51.

(31) Fan Z.; Rahimi P.; McGee R.; Wen Q, Alem T. Investigation of fouling mechanisms of a light crude oil using an alcor hot liquid process simulator. Energy and Fuels. 2010;24(11):61106118. doi:10.1021/ef101097c.

(32) Young A.; Venditti S.; Berrueco C.; Yang M.; Waters A.; Davies H.; Hill S.; Millan M.; Crittenden B. Characterization of Crude Oils and Their Fouling Deposits Using a Batch Stirred 
Cell System. Heat Transf Eng. 2011;32(3-4):216-227.

(33) Joshi H. M. Analysis of Field Fouling Deposits from Crude Heat Exchangers. In: Coletti F, Hewitt GF, eds. Crude Oil Fouling: Deposit Characterization, Measurements, and Modeling. Boston: Gulf Professional Publishing; 2014.

(34) Mozdianfard M.R.; Behranvand E. Fouling at post desalter and preflash drum heat exchangers of CDU preheat train. Appl Therm Eng. 2015;89:783-794. doi:10.1016/j.applthermaleng.2015.06.045.

(35) Bott T.R. Fouling of Heat Exchangers. 1st ed. Amsterdam: Elsevier Science; 1995.

(36) Shackelford J.F.; Alexander W. CRC Materials Science and Engineering Handbook. 3rd ed. London: CRC press; 2000.

(37) Wang W.; Watkinson A.P. Iron Sulphide and coke fouling from sour oils: review and initial experiments. In: Malayeri MR, Müller-Steinhagen H, Watkinson AP, eds. Int. Conf. on Heat Exchanger Fouling and Cleaning 2011. Vol 2011. Crete Island, Greece; 2011:23-30.

(38) Díaz-Bejarano E.; Coletti F.; Macchietto S. Detection of Changes in Fouling Behavior by Simultaneous Monitoring of Thermal and Hydraulic Performance of Refinery Heat Exchangers. Computer Aided Chemical Engineering. 2015, 37:1649-1654. doi:10.1016/B9780-444-63577-8.50120-0.

(39) Díaz-Bejarano E.; Coletti F.; Macchietto S. Model-Based Monitoring of Thermal-Hydraulic Performance of Refinery Heat Exchangers Undergoing Fouling. Computer Aided Chemical Engineering. 2016, 38:1911-1916. doi:10.1016/B978-0-444-63428-3.50323-4.

(40) Wang W.; Watkinson AP. Deposition From a Sour Heavy Oil Under Incipient Coking Conditions: Effect of Surface Materials and Temperature. Heat Transf Eng. 2015;36(7-8):623631. doi:10.1080/01457632.2015.954914.

(41) Hazelton M.; Stephenson T.; Lepore J.; Subramani V.; Mitlin D. Sulfide promoted chronic fouling in a refinery: A broad phenomenon spanning a range of heat transfer surfaces and oil types. Fuel. 2015;160:479-489. doi:10.1016/j.fuel.2015.07.074.

(42) Coletti F.; Macchietto S. A Dynamic, Distributed Model of Shell-and-Tube Heat Exchangers Undergoing Crude Oil Fouling. Ind Eng Chem Res. 2011;50(8):4515-4533. 
doi:10.1021/ie901991g.

(43) Hexxcell Ltd. Hexxcell Studio. http://www.hexxcell.com, 2018.

(44) Saunders EAD. Heat Exchangers: Selection, Design, and Construction. Longman, Harlow; 1988.

(45) Taborek J. Shell-and-tube heat exchangers: single phase flow. In: Hewitt GF, ed. Heat Exchanger Design Handbook. New York: Begell House; 2002.

(46) Holman JP. Heat Transfer. 8th ed. London: McGraw-Hill; 2001.

(47) Wang J.; Carson J.K.; North M.F.; Cleland D.J. A new structural model of effective thermal conductivity for heterogeneous materials with co-continuous phases. Int J Heat Mass Transf. 2008;51(9-10):2389-2397.

(48) Box GEP. Fitting empirical data. Ann N Y Acad Sci. 1960;86:792-816.

(49) Watkinson A.P.; Navaneetha-Sundaram B.; Posarac D. Fouling of a sweet crude oil under inert and oxygenated conditions. Energy and Fuels. 2000;14(11):64-69.

(50) Stephenson T.; Hazelton M.; Kupsta M.; Lepore J.; Andreassen E.J.; Hoff A.; Newman B.; Eaton P.; Gray M.; Mitlin D. Thiophene mitigates high temperature fouling of metal surfaces in oil refining. Fuel. 2015;139:411-424. doi:10.1016/j.fuel.2014.08.049.

(51) Mozdianfard M.R.; Behranvand E. A field study of fouling in CDU preheaters at Esfahan refinery. Appl Therm Eng. 2013;50(1):908-917. doi:10.1016/j.applthermaleng.2012.08.025.

(52) Francia V.; Martin L.; Bayly A.E.; Simmons M.J.H. The Role of Wall Deposition and ReEntrainment in Swirl Spray Dryers. AIChE J. 2015;61(6):1804-1821.

(53) Watkinson A. P. Deposition from Crude Oils in Heat Exchangers. Heat Transf Eng. 2007;28(3):177-184. doi:10.1080/01457630601064413.

(54) Henry C.; Minier J-P.; Lefèvre G. Towards a description of particulate fouling: From single particle deposition to clogging. Adv Colloid Interface Sci. 2012;185-186:34-76. doi:10.1016/j.cis.2012.10.001.

(55) Process Systems Enterprise, gPROMS. www.psenterprise.com/gproms, 1997-2018.

(56) Espie D.M.; Macchietto S. Nonlinear transformations for parameter estimation. Ind Eng Chem Res. 1988;27(11):2175-2179. doi:10.1021/ie00083a037. 
(57) Chunangad K.S.; Chang R.Y.; Casebolt R.P. Evaluation and Prediction of the Thermal and Hydraulic Impact of Crude Oil Fouling on Exchanger Performance using Pressure Measurements. In: Heat Exchanger Fouling and Cleaning - 2017. Aranjuez (Madrid), Spain; 2017:1-4. 
Table 1. Main equations of the model

\section{Heat Exchanger Model (Coletti and Macchietto ${ }^{42}$ )}

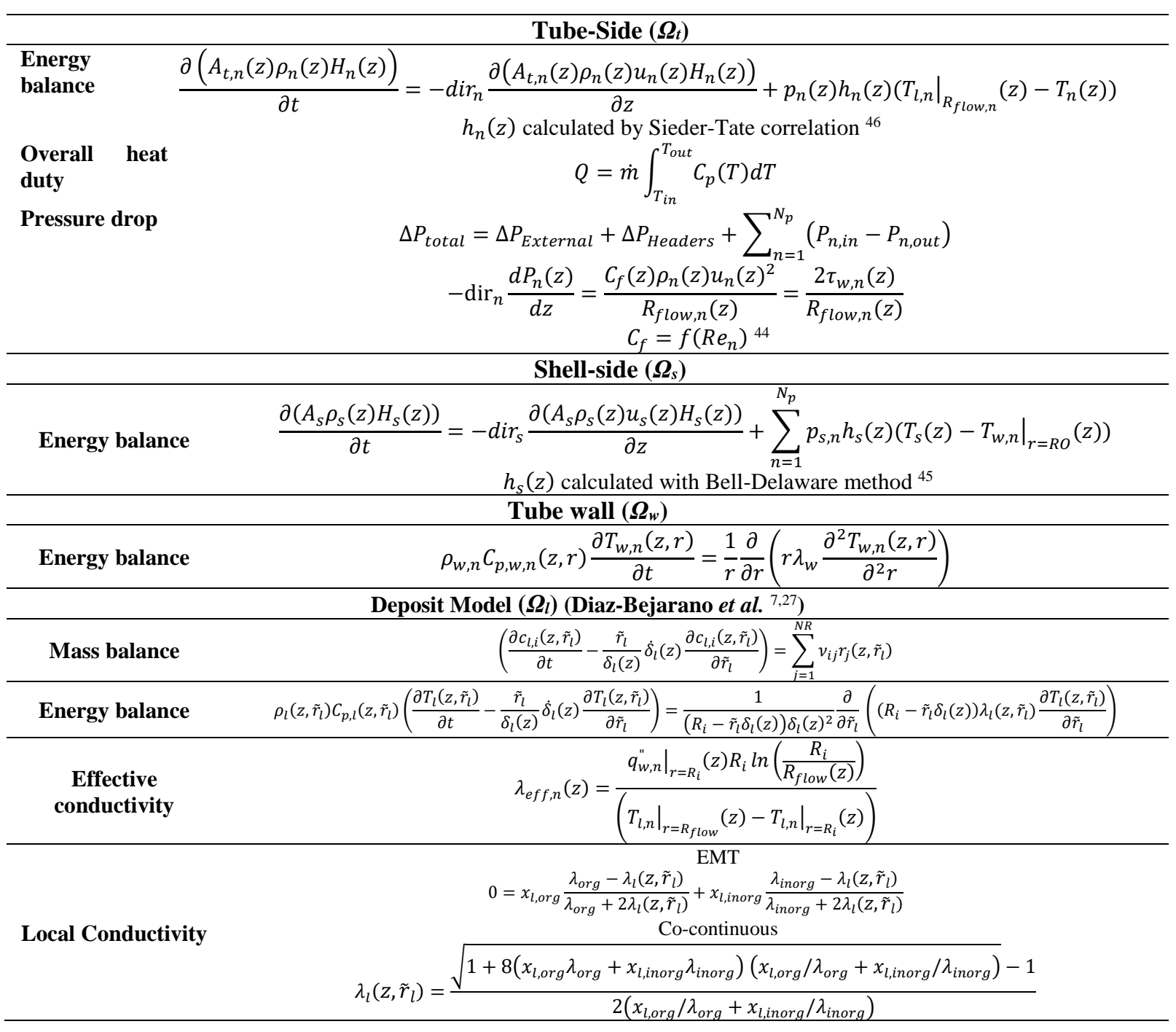

Table 2: Estimation of reference deposition rate model parameters

\begin{tabular}{|c|c|c|c|c|c|c|c|c|c|c|c|}
\hline \multirow[b]{2}{*}{ Case } & \multirow[b]{2}{*}{$p_{\text {inorg }}$} & \multicolumn{3}{|c|}{ Optimal Estimate } & \multirow[t]{2}{*}{$\chi^{2}$} & \multicolumn{3}{|c|}{$95 \%$ t-value } & \multicolumn{3}{|c|}{ Correlation } \\
\hline & & $\begin{array}{c}\alpha^{\prime} \\
\left(\operatorname{kggl}_{\mathrm{gel}} \mathbf{m}^{-2} \mathbf{s}^{-1}\right)\end{array}$ & $\begin{array}{c}10^{9} \gamma^{\prime} \\
\left(\mathrm{kg}_{\mathrm{gel}} \mathrm{m}^{-2} \mathrm{~s}^{-1} \mathbf{P a}^{-1}\right)\end{array}$ & $p_{i / o}$ & & $\alpha^{\prime}$ & $\gamma^{\prime}$ & $p_{i / o}$ & $\alpha^{\prime}-\gamma^{\prime}$ & $\alpha^{\prime}-p_{i / o}$ & $\gamma^{\prime}-p_{i / o}$ \\
\hline A & $\begin{array}{c}\approx 0.7\left(\lambda_{l}=0.93\right. \\
\left.\mathrm{Wm}^{-1} \mathrm{~K}^{-1}\right)\end{array}$ & $1.08 \pm 0.04$ & $2.33 \pm 0.12$ & - & 1134 & 844 & 34 & - & $0.98^{*}$ & - & - \\
\hline B & $\begin{array}{c}\text { Time-varying } \\
\text { (EMT) }\end{array}$ & $0.92 \pm 0.02$ & $1.83 \pm 0.07$ & - & 1005 & 839 & 27 & - & $0.98^{*}$ & - & - \\
\hline $\mathbf{C}$ & Time-varying $(\mathrm{CC})$ & $0.70 \pm 0.02$ & $1.23 \pm 0.06$ & - & 768 & 801 & 22 & - & $0.98^{*}$ & - & - \\
\hline D & $\begin{array}{c}\text { Time-varying, } \\
\text { reinforcing (EMT) }\end{array}$ & $0.55 \pm 0.05$ & $0.93 \pm 0.13$ & $\begin{array}{c}0.24 \pm \\
0.01 \\
\end{array}$ & 841 & 195 & 7.2 & 23 & $0.99 *$ & $-0.97 *$ & -0.92 \\
\hline $\mathbf{E}$ & $\begin{array}{l}\text { Time-varying, } \\
\text { reinforcing }(\mathrm{CC})\end{array}$ & $0.66 \pm 0.06$ & $1.13 \pm 0.15$ & $\begin{array}{c}0.013 \pm \\
0.015\end{array}$ & 766 & 198 & 7.6 & $0.9^{* *}$ & $0.99^{*}$ & $-0.97 *$ & -0.93 \\
\hline \multicolumn{5}{|c|}{ Reference value for statistics } & 1266 & \multicolumn{3}{|c|}{1.646} & & & \\
\hline
\end{tabular}

\footnotetext{
*High correlation; $* * \mathrm{t}<\mathrm{tref}$, low confidence in the value
} 


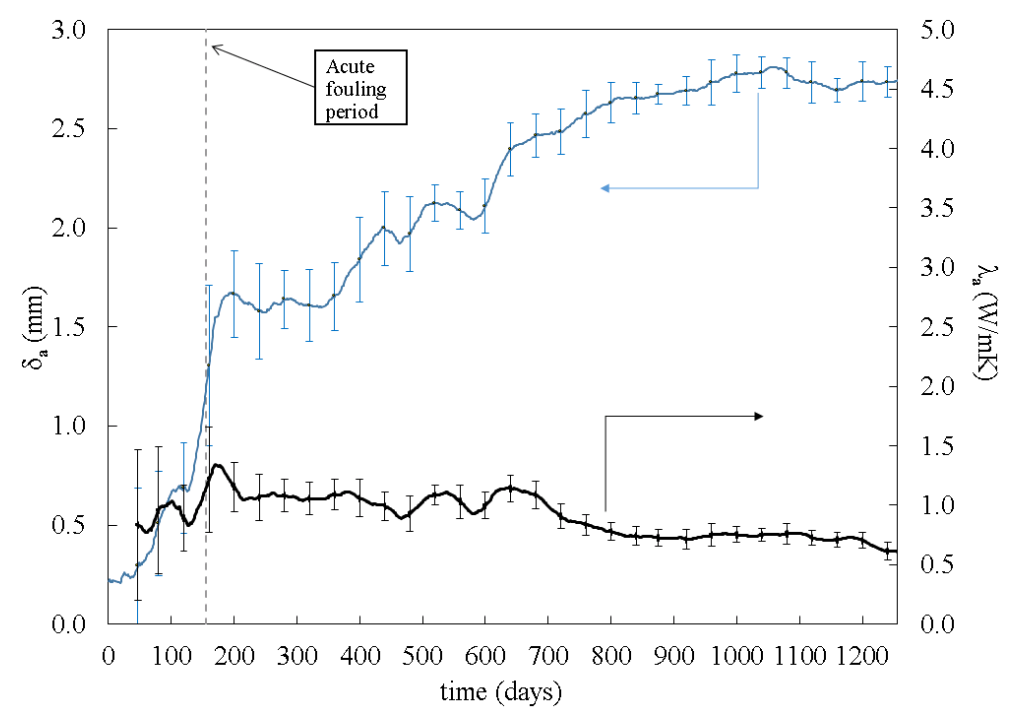

Figure 1. Apparent thickness and thermal-conductivity. Error bars represent $\pm 2 \sigma$. Adapted with permission from ${ }^{7}$.
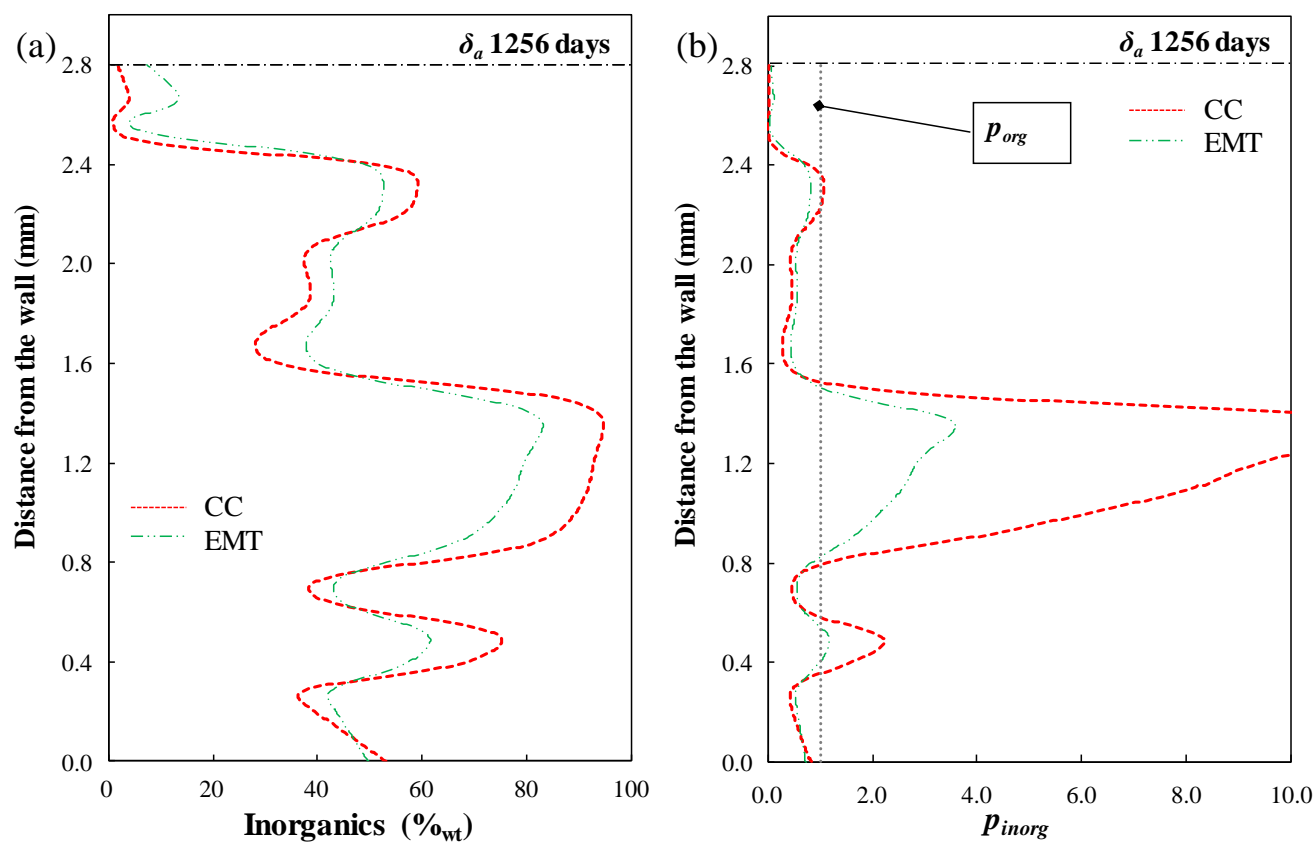

Figure 2. Calculated inorganic content radial profile (a) and corresponding deposition rate ratios (b) for EMT and CC conductivity models. Figure (a) adapted with permission from ${ }^{7}$. 
(a)

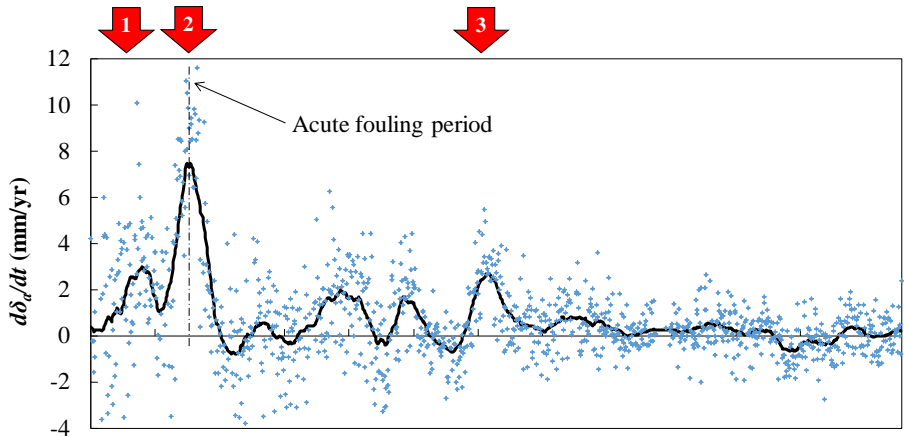

(b)

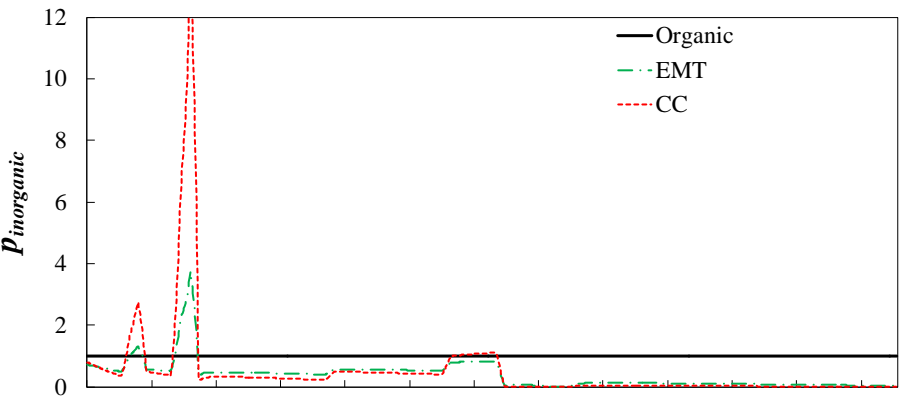

(c)

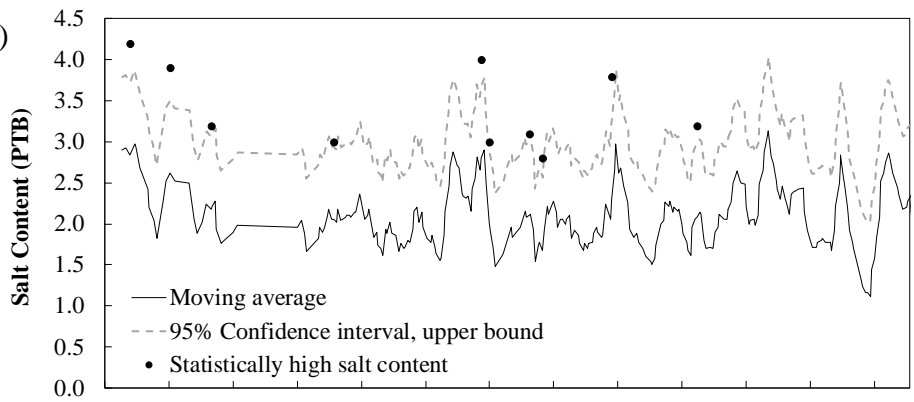

(d)

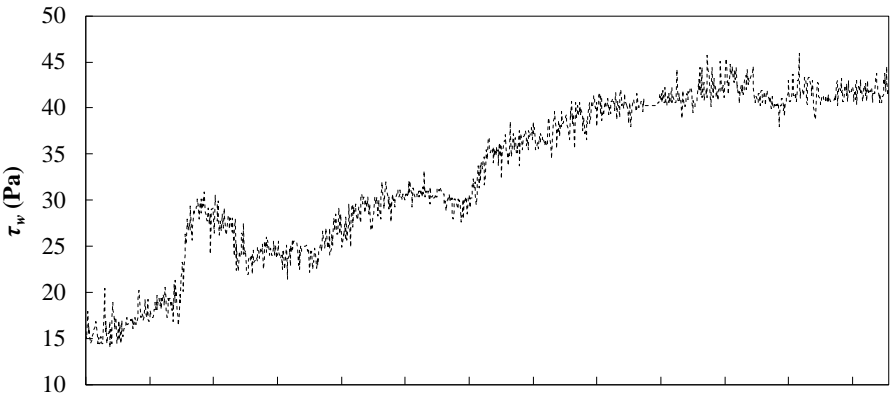

(e)

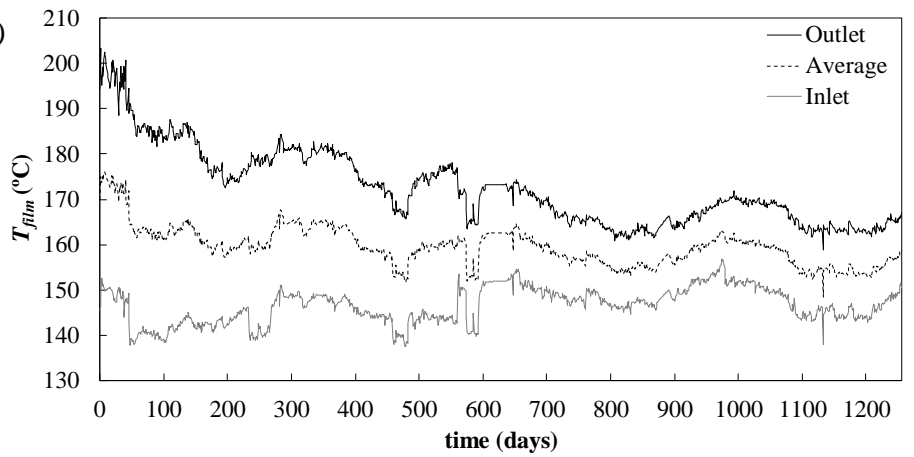

Figure 3: (a) Apparent deposition rate over time (dots) and moving average (continuous line); (b) inorganic-to-organic fouling rate ratio (from Figure 2b); (c) Salt content in crude oil entering E155AB; (d) Calculated wall shear stress; (e) Calculated film temperature. 


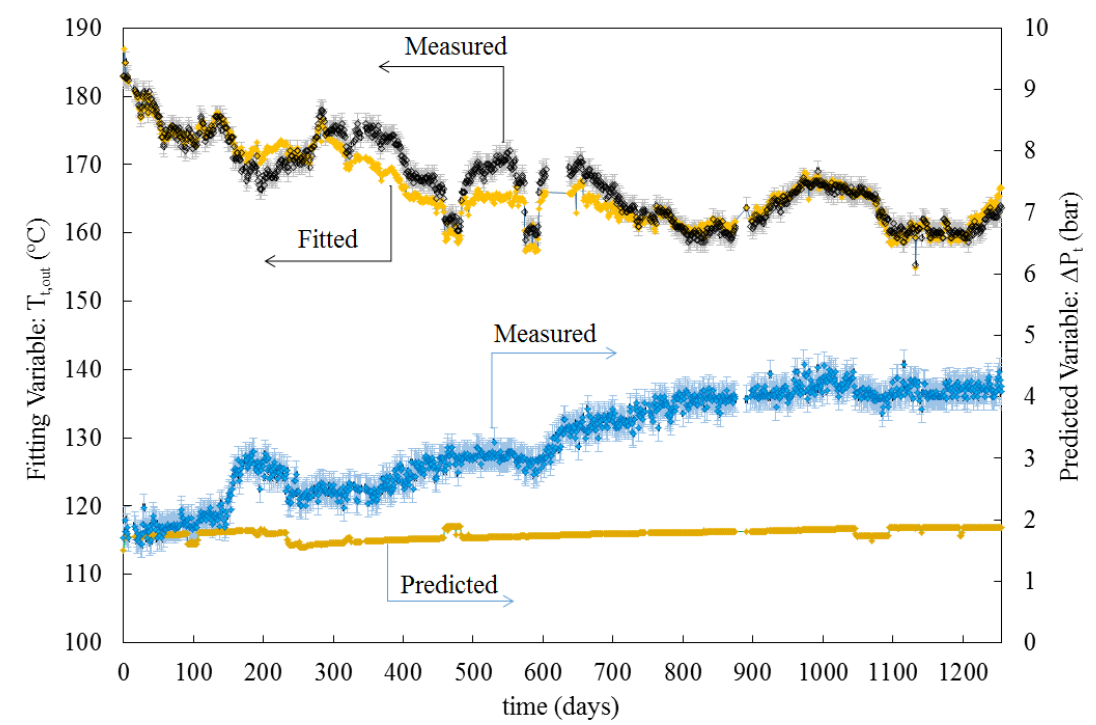

Figure 4: Case 0T - Estimation based on temperatures assuming organic fouling. Measured vs. fitted tube outlet temperature and measured vs. predicted pressure drop.

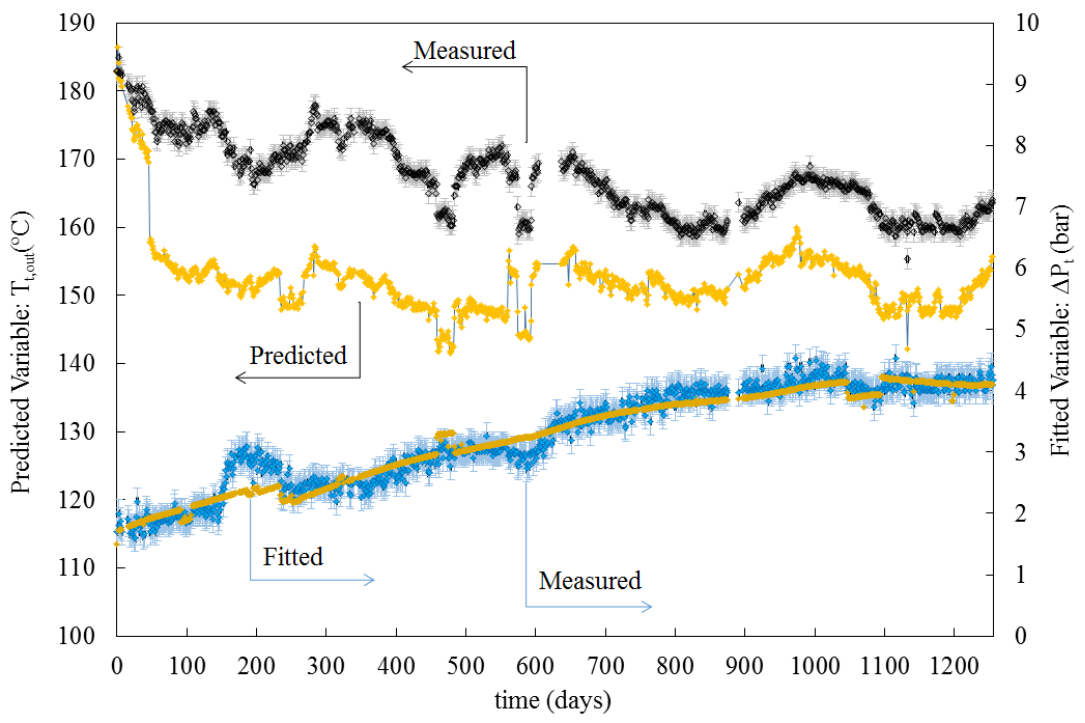

Figure 5: Case OP - Estimation based on pressure drop assuming organic fouling. Measured vs. predicted tube outlet temperature and measured vs. fitted pressure drop. 


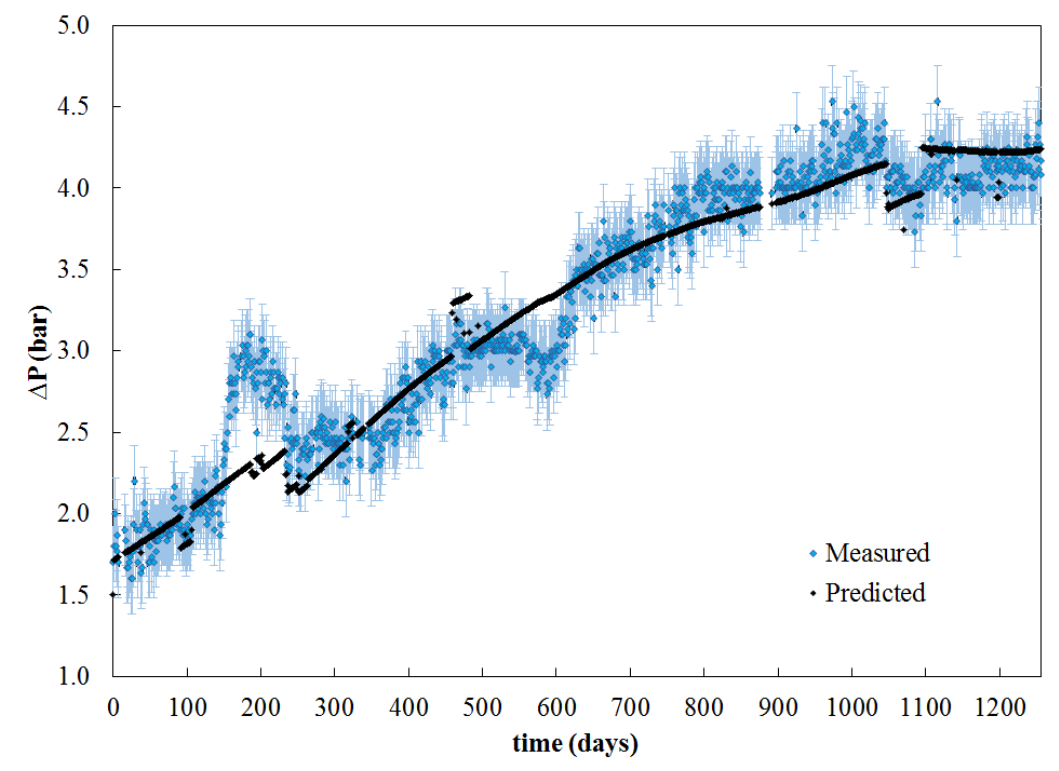

(a)

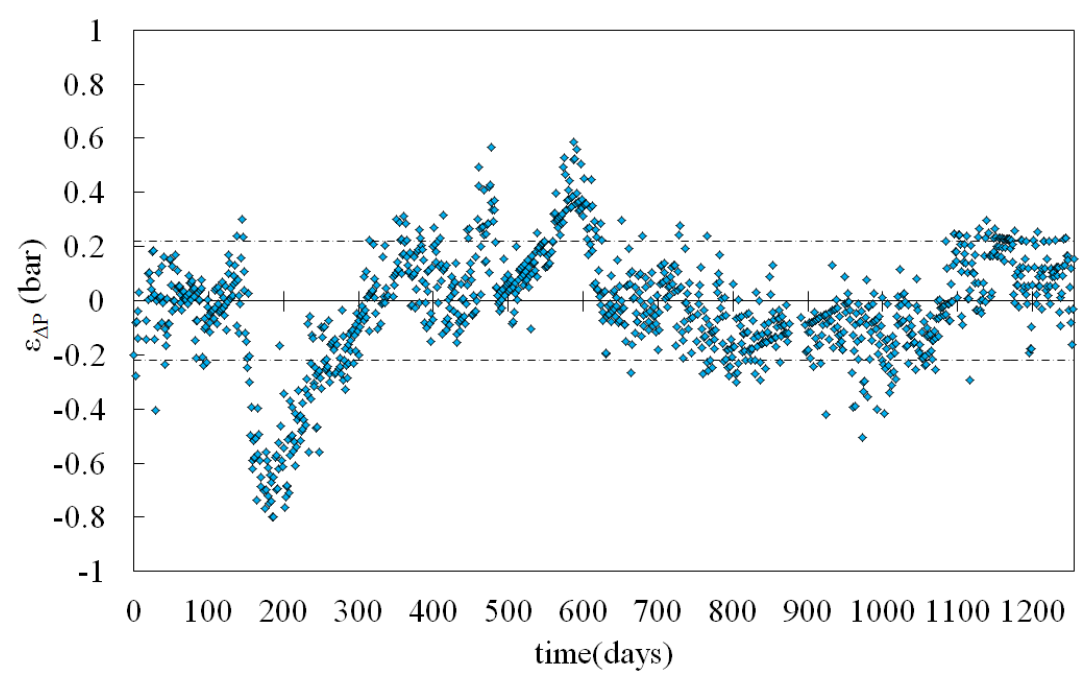

(b)

Figure 6: Case A - Estimation with uniform pinorg: measured vs. fitted pressure drop (a) and residuals ( $\varepsilon=$ simulated - measured) (b). Error bars in (a) and dashed lines in (b) indicate $\pm 1 \sigma$. 


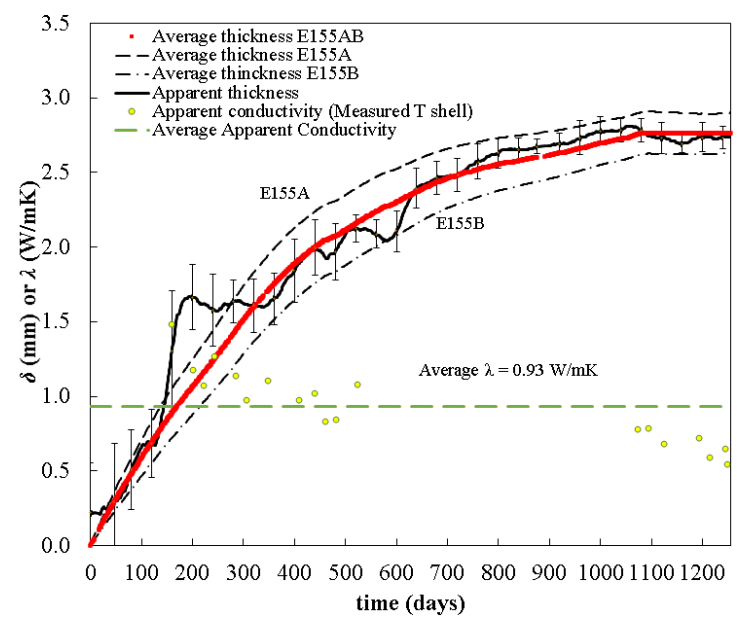

(a)

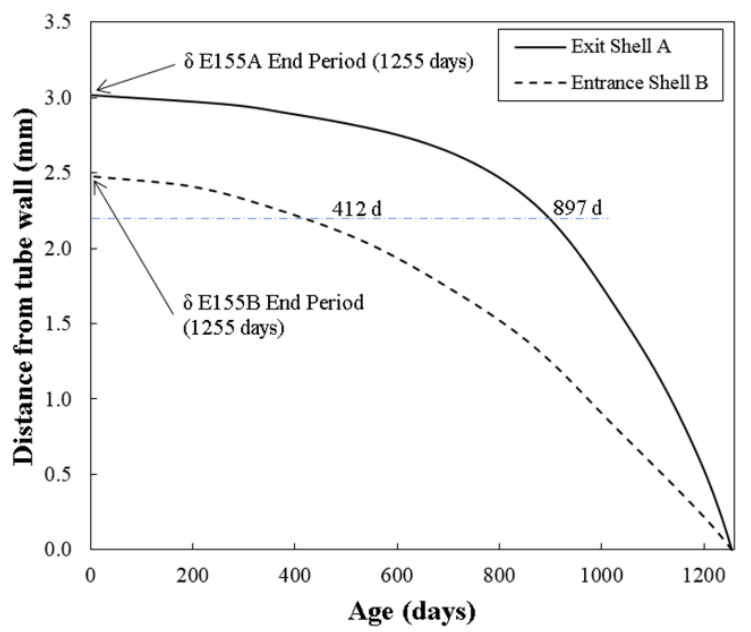

(b)

Figure 7: Case A - Uniform pinorg: (a) Average thickness (for each shell and average), apparent thickness, apparent conductivity and fixed average conductivity; (b) Age of deposit at the entrance of E155B (the coldest end) and exit of E155A (the hottest end) at the end of the operating period.

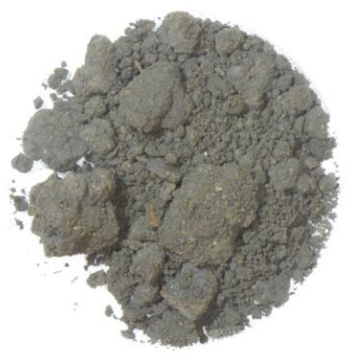

(a)

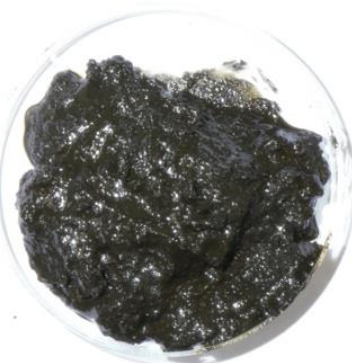

(b)

Figure 8: Scraped tube-side deposit for hotter shell E155A (a), colder shell E155B (b). Reprinted with permission from ${ }^{7}$. 


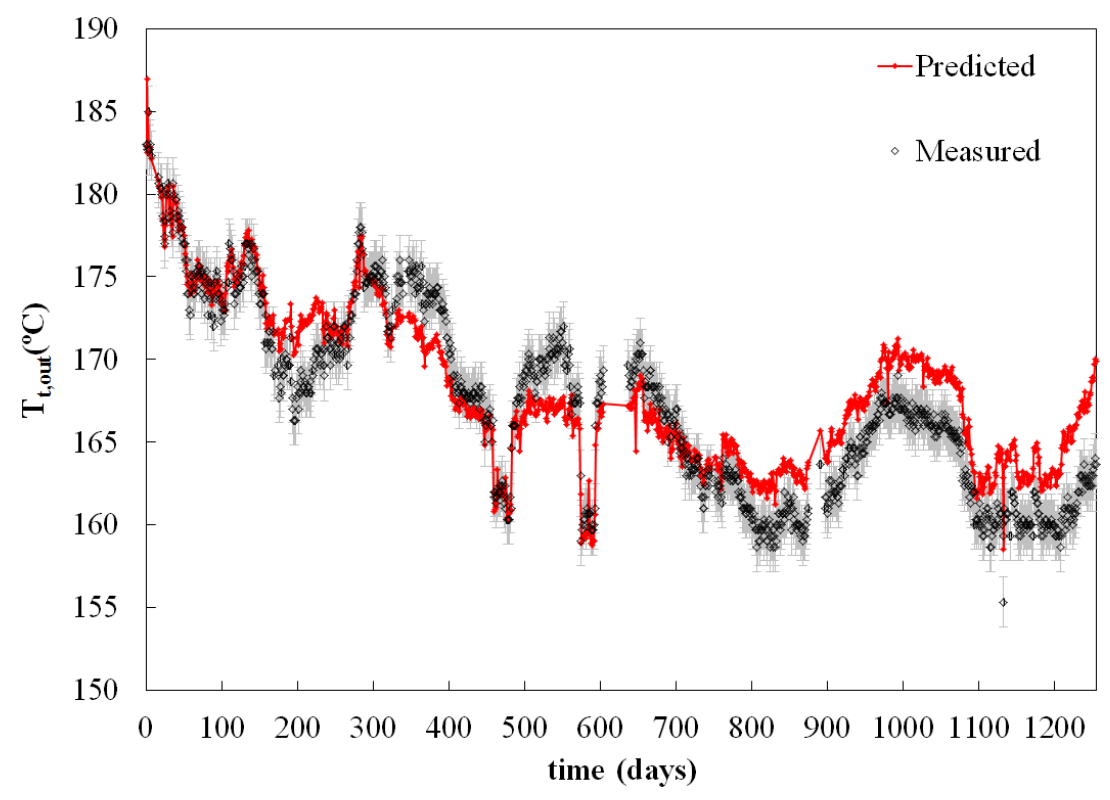

(a)

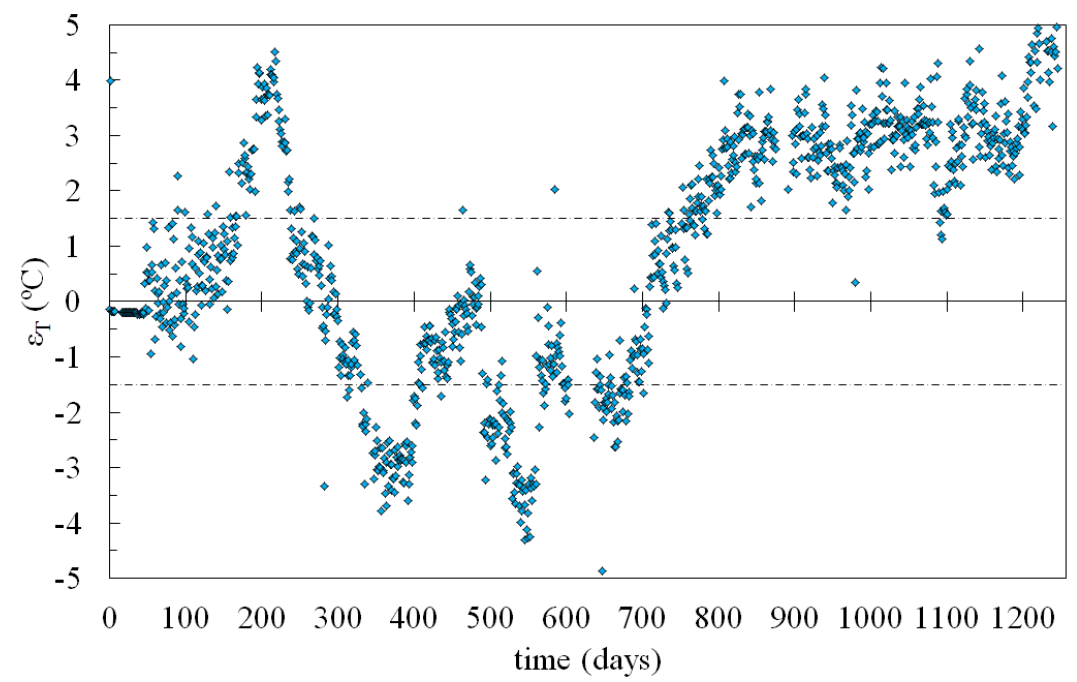

(b)

Figure 9: Case A - Uniform $p_{\text {inorg }}$ : Predicted tube outlet temperature vs. measurements (a) and residuals $(\varepsilon=$ simulated - measured) (b). Error bars in (a) and dashed lines in (b) indicate $\pm 1 \sigma$. 


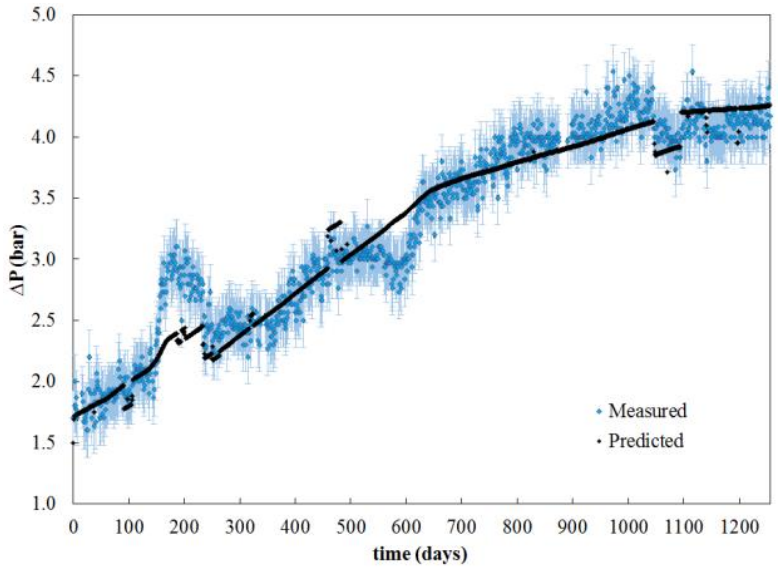

(a)

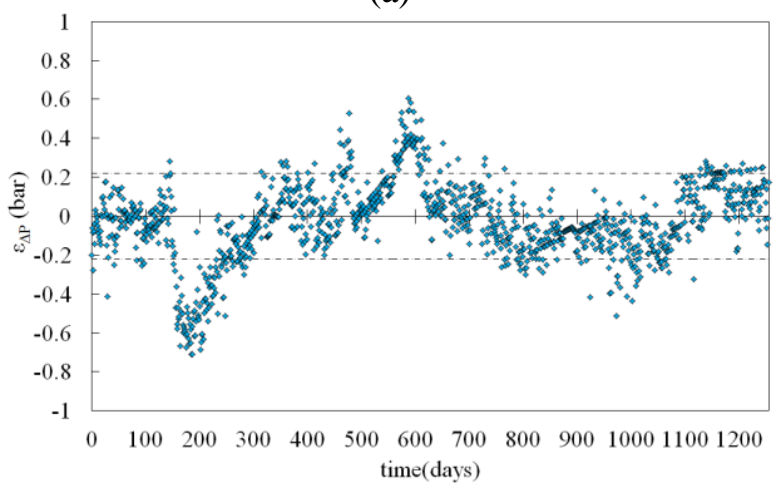

(c)

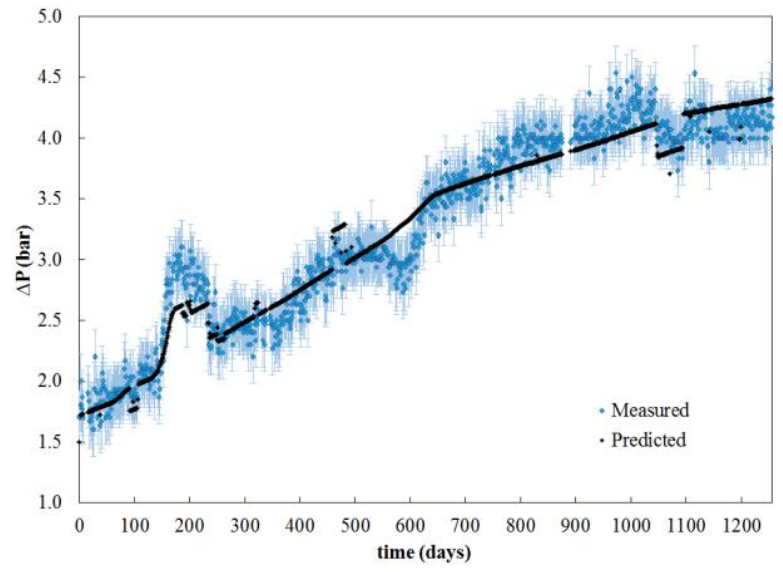

(b)

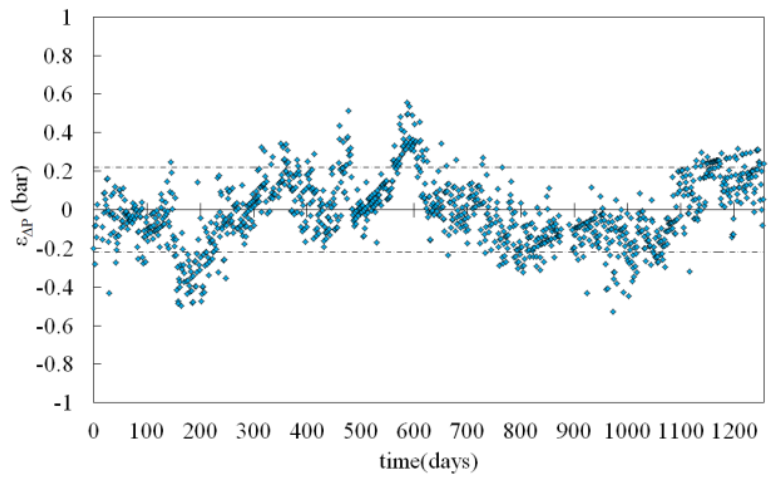

(d)

Figure 10: Cases B and C - Estimation with time-varying $p_{\text {inorg }}$ with EMT and CC models: measured versus fitted pressure drop ( $\mathrm{a}$ and $\mathrm{b}$, respectively) and corresponding residuals $(\varepsilon=$ simulated - measured) (c and d, respectively).

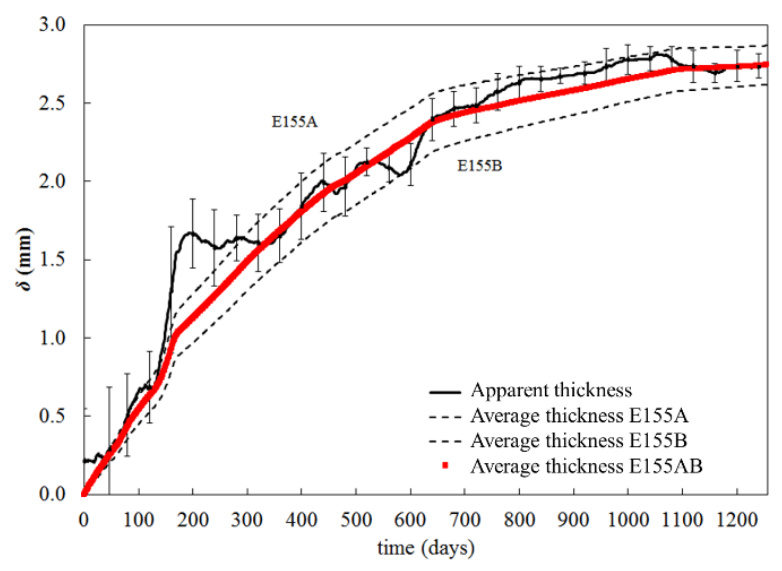

(a)

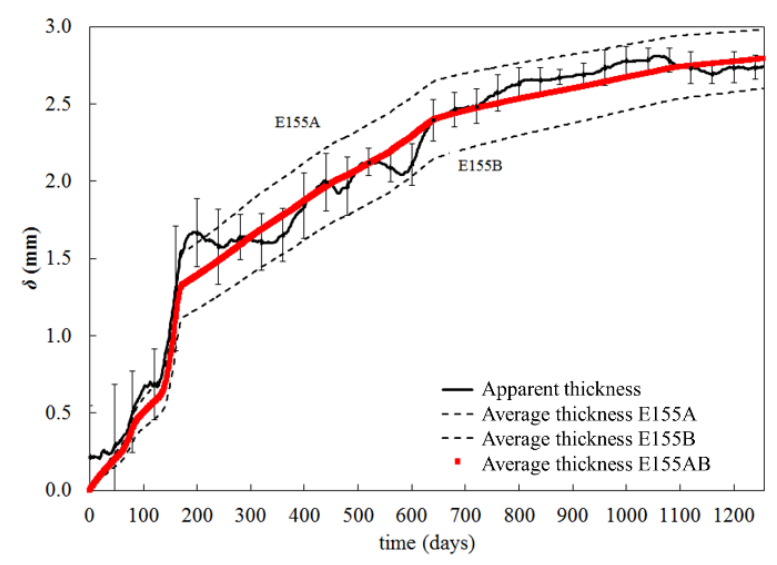

(b)

Figure 11: Cases B and C - Time-varying $p_{\text {inorg }}$ with EMT (a) and CC (b) models: Average thickness (for each shell and average) and apparent thickness. 


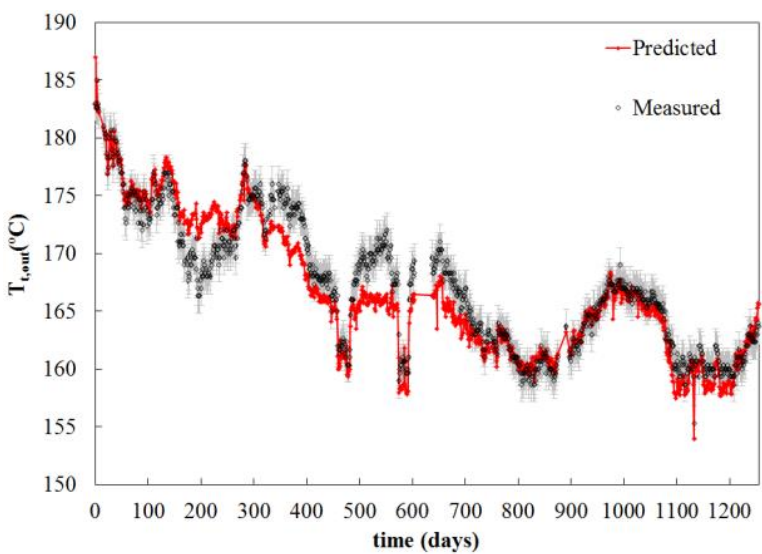

(a)

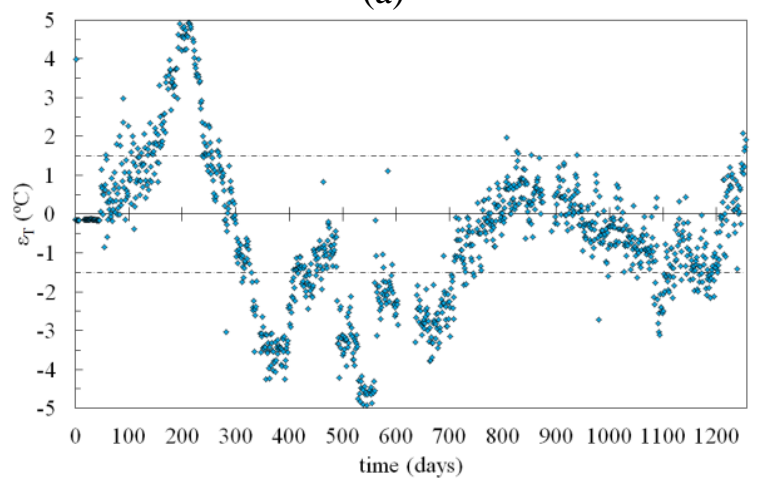

(c)

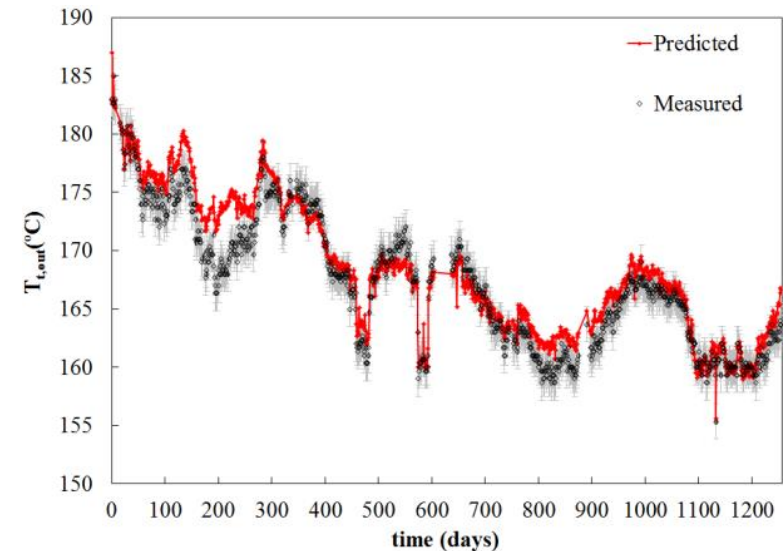

(b)

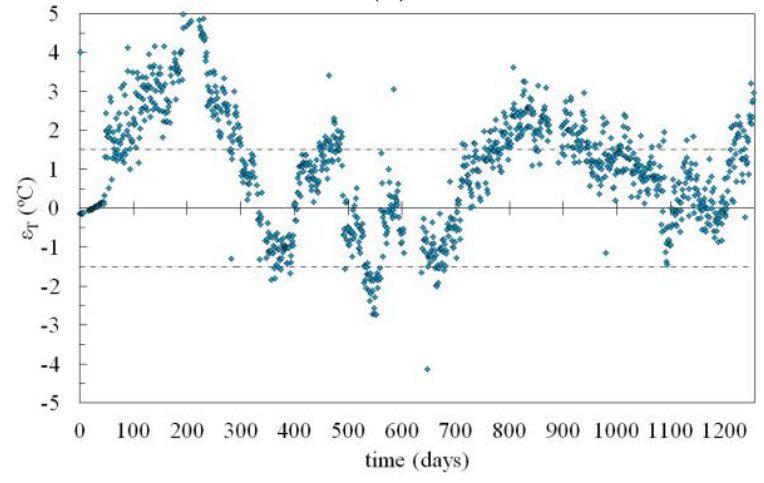

(d)

Figure 12: Cases $B$ and $C$ - Time-varying p pinorg with EMT and $C C$ models: measured versus predicted tube-side outlet temperature ( $\mathrm{a}$ and $\mathrm{b}$, respectively) and corresponding residuals $(\varepsilon=$ simulated - measured $)(\mathrm{c}$ and $\mathrm{d}$, respectively).

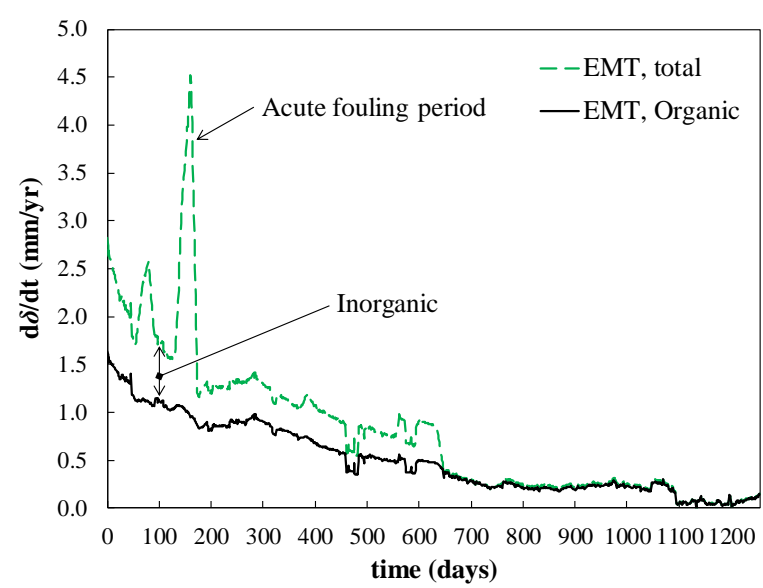

(a)

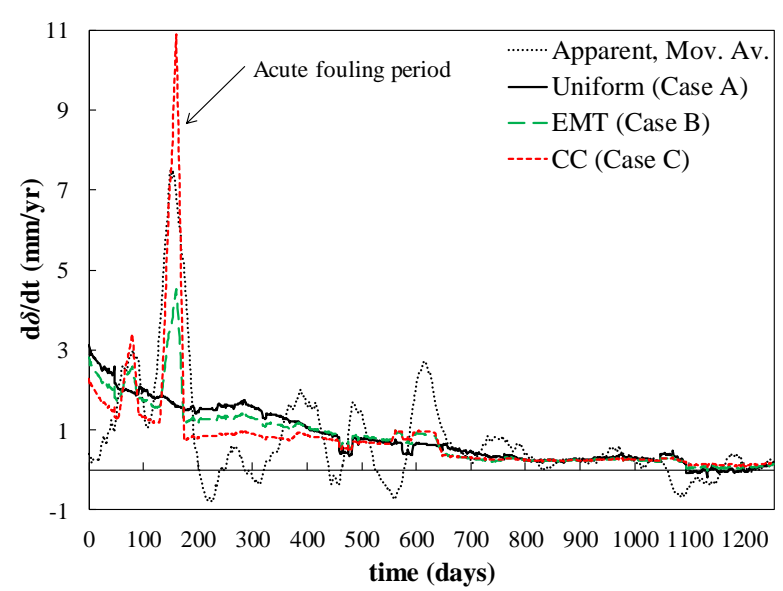

(b)

Figure 13: (a) Organic deposition rate and total deposition rate in Case B; (b) Comparison of average net deposition rate for Cases $\mathrm{A}, \mathrm{B}$ and $\mathrm{C}$ with apparent deposition rate (moving average). 


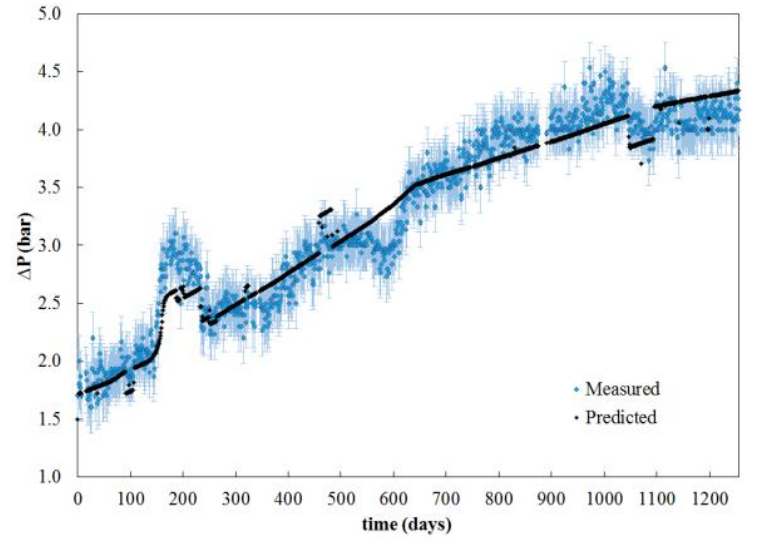

(a)

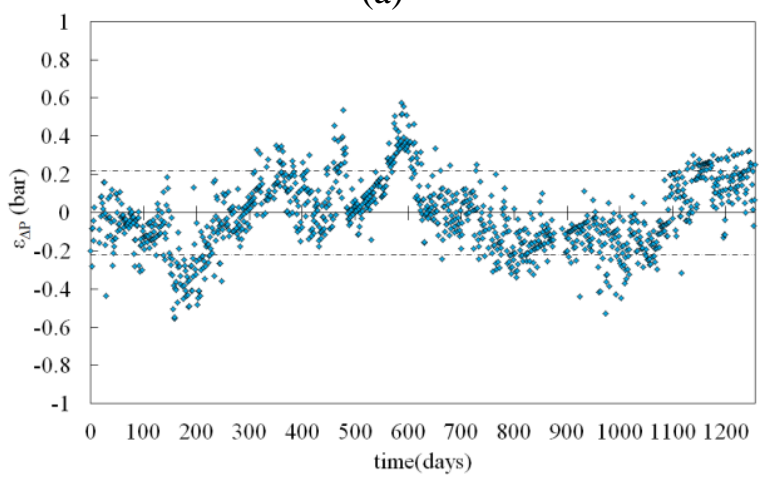

(c)

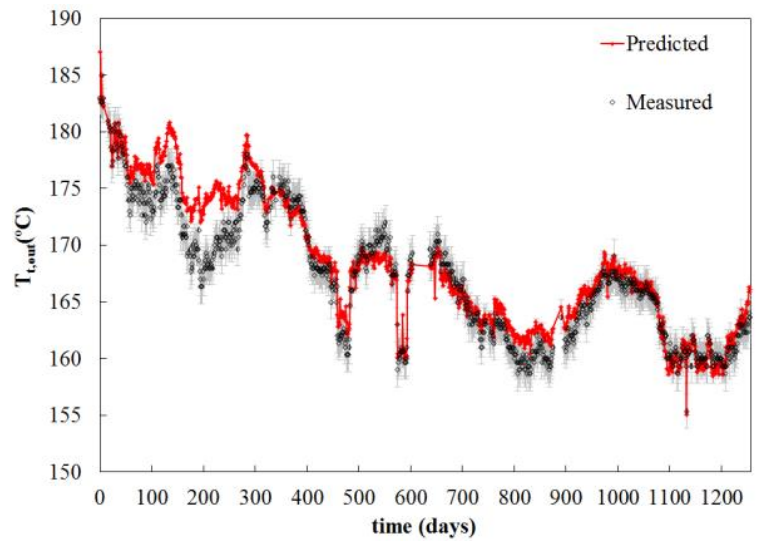

(b)

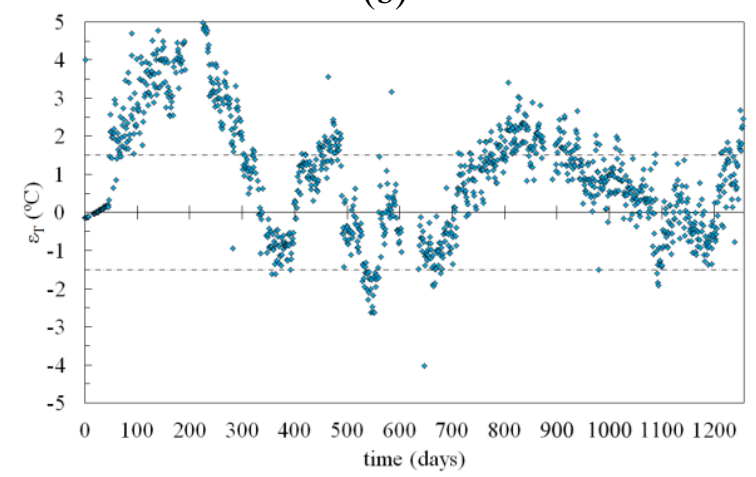

(d)

Figure 14: Case D - Time-varying $p_{\text {inorganic }}$ and reinforcing effect with EMT: measured vs. fitted pressure drop (a), measured vs. predicted tube-side outlet temperature (b), and corresponding residuals $(\varepsilon=$ simulated - measured $)(c)$ and $(d)$, respectively.

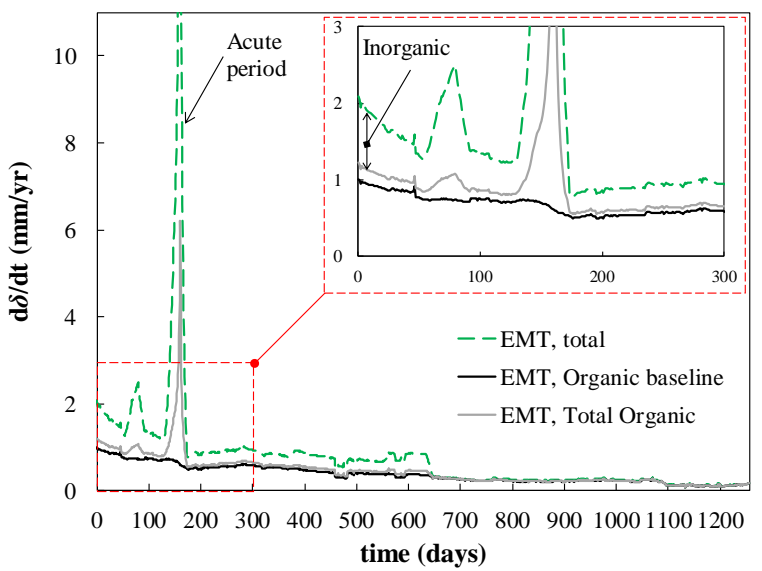

(a)

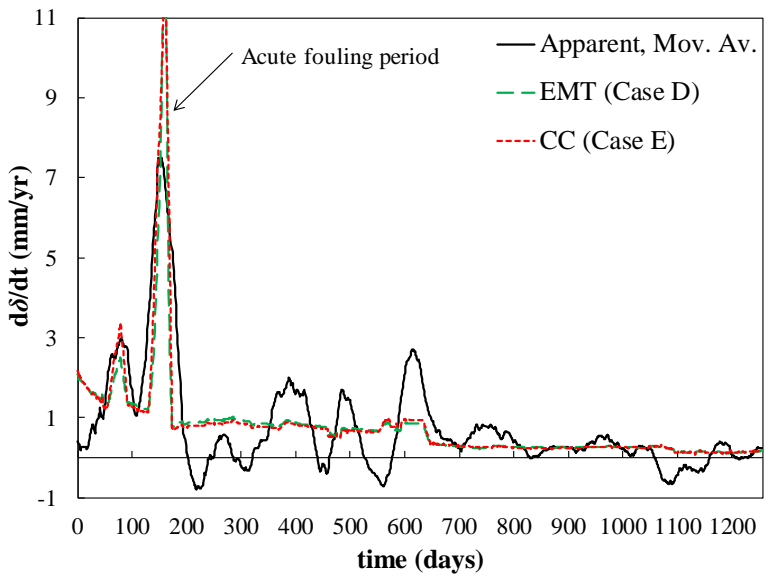

(b)

Figure 15: (a) Organic deposition rate (baseline and total) and total deposition rate in Case D; (b) Comparison of average net deposition rate for Cases $\mathrm{D}$ and $\mathrm{E}$ with apparent deposition rate (moving average). 


\section{TOC}

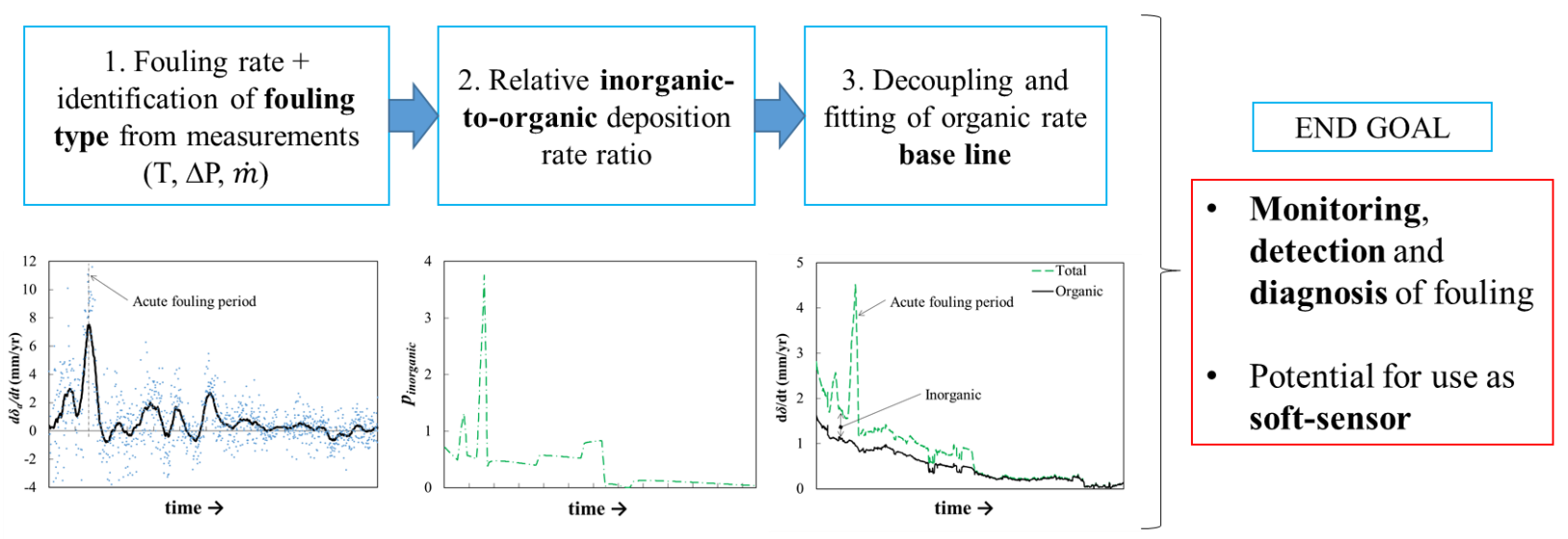

